\title{
A role for Lin28a in aging-associated decline of adult hippocampal neurogenesis
}

\author{
Zhechun Hu, ${ }^{1,7}$ Jiao Ma, ${ }^{2,7}$ Huimin Yue, ${ }^{1}$ Xiaofang Li, ${ }^{2}$ Chao Wang, ${ }^{1}$ Liang Wang, ${ }^{3}$ Binggui Sun, ${ }^{4,6}$ \\ Zhong Chen, ${ }^{5}$ Lang Wang, ${ }^{2 *}$ Yan $\mathrm{Gu}^{1,6^{*}}$
}

\section{Affiliations}

${ }^{1}$ Center of Stem Cell and Regenerative Medicine, and Department of Neurology of the Second Affiliated Hospital, NHC and CAMS Key Laboratory of Medical Neurobiology, Zhejiang University School of Medicine, Hangzhou 310058, China

${ }^{2}$ Department of Neurology of the First Affiliated Hospital, Interdisciplinary Institute of Neuroscience and Technology, Zhejiang University School of Medicine, Hangzhou 310029, China

${ }^{3}$ Institute of Neuroscience and Department of Neurology of the Second Affiliated Hospital, Mental Health Center, NHC and CAMS Key Laboratory of Medical Neurobiology, Zhejiang University School of Medicine, Hangzhou 310058, China

${ }^{4} \mathrm{NHC}$ and CAMS Key Laboratory of Medical Neurobiology, School of Brain Science and Brain Medicine, Zhejiang University, Hangzhou 310058, China

${ }^{5}$ Key Laboratory of Neuropharmacology and Translational Medicine of Zhejiang Province, School of Pharmaceutical Sciences, Zhejiang Chinese Medical University, Hangzhou 310053, China

${ }^{6} \mathrm{MOE}$ Frontier Science Center for Brain Science \& Brain-Machine Integration, Zhejiang University, Hangzhou 310058, China

${ }^{7}$ These authors contributed equally to this work

*Correspondence should be addressed to Yan Gu at guyan2015@zju.edu.cn or Lang Wang at wanglang@zju.edu.cn 


\begin{abstract}
Hippocampal neurogenesis declines with aging. Wnt ligands and antagonists within the hippocampal neurogenic niche regulate the proliferation of neural progenitor cells and the development of new neurons, and the changes of their levels in the niche mediate aging-associated decline of neurogenesis. We found that RNA-binding protein Lin28a remained existent in neural progenitor cells and granule neurons in the adult hippocampus, and decreased with aging. Loss of Lin28a inhibited the responsiveness of neural progenitor cells to niche Wnt agonist and reduced neurogenesis, thus impairing pattern separation. Overexpression of Lin28a increased the proliferation of neural progenitor cells, promoted the functional integration of newborn neurons, restored neurogenesis in Wnt-deficient dentate gyrus, and rescued the impaired pattern separation in aging mice. Our data suggest that Lin28a regulates adult hippocampal neurogenesis as an intracellular mechanism by responding to niche Wnt signals, and its decrease is involved in aging-associated decline of hippocampal neurogenesis as well as related cognitive functions.
\end{abstract}

Keywords: adult neurogenesis/aging/hippocampus/Lin28a/Wnt 


\section{Introduction}

In the adult mammalian hippocampus, neural stem cells in the subgranular zone (SGZ) of the dentate gyrus (DG) give rise to newborn neurons throughout life (Ming and Song, 2011). Continuously generated newborn neurons integrate into the existing neural circuits, and play essential roles for hippocampal functions, such as hippocampus-dependent mood regulation, memory coding and pattern separation (Anacker and Hen, 2017; Christian et al., 2014; Goncalves et al., 2016).

Accumulating evidence indicates that the proliferative activity of neural progenitor cells (NPCs) and the integration of newborn neurons decrease with aging, resulting in an age-associated decay of neurogenesis (Kuhn et al., 1996; Ngwenya et al., 2015; Spalding et al., 2013), which is believed to be associated with declines in hippocampal-dependent cognitive functions (Seib et al., 2013). Among all the regulating factors, Wnt ligands and antagonists are secreted by local astrocytes and/or neurons in the neurogenic niche, and play essential roles in regulating both the proliferation of NPCs and the development of newborn neurons (Jang et al., 2013; Kuwabara et al., 2009; Lie et al., 2005; Song et al., 2002). Importantly, Wnt signals in the neurogenic niches change dynamically, thus providing a timely regulation of neurogenesis in the adult hippocampus. For instance, Wnt antagonists in the local microenvironment, such as secreted frizzled-related protein 3 (sFRP3) and dickkopf 1 (Dkk1), are important regulators for hippocampal neurogenesis in response to activity and aging (Jang et al., 2013; Seib et al., 2013). However, the intracellular mechanisms underlying Wnt-related regulation of neurogenesis have not been fully revealed.

Lin28 is an RNA-binding protein with a cold-shock domain and a pair of CCHC zinc knuckle RNAbinding domains (Moss et al., 1997). Lin28 has been known to function as a key regulator for self-renewal of embryonic stem cells, and generation of induced pluripotent stem cells (iPSCs) from somatic cells together with Sox2, Oct4 and Nanog (Yu et al., 2007). Recent evidence suggests that Lin28 also plays essential roles in a variety of biological processes, including tissue growth, metabolisms and cancers (Shyh-Chang and Daley, 2013). The two homologs of Lin28 in mammals, Lin28a and Lin28b, are highly expressed during 
early embryonic development but are thought to be silenced in most adult tissues (Viswanathan and Daley, 2010).

In the developing nervous system, Lin28a has been found to be highly expressed in the NPCs in neural tube during early embryonic stage and at the ventricular/subventricular zone (VZ/SVZ) of the developing cerebral cortex, regulating the generation of neurons and early brain development (Balzer et al., 2010; Yang et al., 2015). Previous studies showed that Lin28a expression dramatically decreases with brain development (Yang et al., 2015). However, recent studies showed that Lin28a remains in NPCs within neurogenic regions in the adult brain and retina (Cimadamore et al., 2013; Yao et al., 2016), raising the possibility that Lin28a may exist and regulate neurogenesis in the adult or even aging brain, which remains elusive.

In this study, we provide the evidence that Lin28a remains in NPCs and neurons in the adult DG and declines with aging. Our results show that Lin28a regulates the proliferation of NPCs and the development of newborn neurons as a downstream intracellular mechanism underlying the regulation of adult neurogenesis by niche Wnt signals. Thus, along with the aging-associated changes of Wnt ligands/inhibitors in the hippocampal neurogenic niche, the decrease of Lin28a in the NPCs serves as one of the intracellular mechanisms mediating the decline of hippocampal neurogenesis. Increasing the expression of Lin28a in hippocampal NPCs in aging mice could rescue their neurogenesis and the ability of pattern separation.

\section{Results}

\section{Expression of Lin28a in the DG of adult brain decreases with aging}

We first set out to examine the presence of Lin28 in the DG, one of the discrete neurogenic regions in the adult mouse brain. We used RNAscope, a high-sensitivity fluorescent in situ hybridization (FISH) method, in brain sections from adult Nestin-GFP mice. Comparing to the signals obtained using negative control (Neg-ctrl) or positive control (Pos-ctrl) probes, Lin28a but not Lin28b mRNA signals exist in the cell 
body layer of the DG (Figure 1A). Specifically, Lin28a mRNA colocalized with the cell bodies of Nestin ${ }^{+}$ neural stem/progenitor cells, and Prox $1^{+}$dentate granule cells (DGCs) (Figure 1B).

To confirm the expression of Lin28a in the adult DG, we next performed immunohistochemistry, and found Lin28a protein exists in the granule cell layer (GCL) of the DG (Figure EV1A). Consistently, Lin28a was observed colocalizing with Nestin $^{+}$NPCs and Prox $1^{+}$DGCs (Figure 1C). In contrast, in NestinCre::Lin28 $\mathrm{a}^{\text {flox/flox }}$ mice $\left(\operatorname{Lin} 28 \mathrm{a}^{\mathrm{f} / \mathrm{f}}\right)$, Lin28a expression was not detected in either the GCL or the SGZ (Figure EV1B).

Interestingly, we found Lin28a protein level in the DG decreased in aging mice (14 months old, 14 mo) compared to young adult mice ( 2 months old, 2 mo) (Figure 1D and E). Using RNAscope, we were able to analyze Lin28a mRNA level in individual cells, reflected by the number of dots marked by Lin28a mRNA probes in each cell, as previously described (Erben and Buonanno, 2019). We found the number of dots per cell became significantly less in 14 mo animals compared with 2 mo animals, in both Nestin ${ }^{+}$NPCs (Figure 1F and G) and Prox $1^{+}$DGCs (Figure 1H and I), indicating an aging-associated decrease of Lin28a expression in these cells.

\section{Lin28a in hippocampal NPCs are essential for neurogenesis and pattern separation}

To find out whether Lin28a decrease in the DG is related to cognitive declines in aging animals, we next trained young adult $(2 \mathrm{mo})$ and aging $(10 \mathrm{mo})$ mice for a series of behavior tests. We found that the 10 mo mice showed decreased novel location recognition (Figure EV2A - C), while the novel object recognition was not affected (Figure EV2D - F). The young and aging animals didn't show significant difference in single-trial contextual fear memory test (Figure EV2G and H). However, when we tested the animals with a pattern separation behavior paradigm (Figure 2A), as previously reported (Sahay et al., 2011a), we found that the 10 mo mice discriminated the two similar contexts $\mathrm{A}$ and $\mathrm{B}$ in the 6 th test session, much later than the 2 mo mice, which showed contextual discrimination in the 4th session (Figure 2B). This result suggested that 
aging is associated with a decreased ability of pattern separation, consistent with previous studies on aging human and non-human primate subjects (Dillon et al., 2017; Ngwenya et al., 2015).

Because pattern separation is believed to be one of the hippocampal functions most related to neurogenesis (Sahay et al., 2011b), we checked the level of neurogenesis in the DG of the 2 mo and 10 mo mice. Indeed, 10 mo mice showed significantly less doublecortin (DCX)-positive cells in the DG (Figure EV2I and J), indicating an aging-associated decline of hippocampal neurogenesis, consistent with previous reports (Seib et al., 2013).

To test whether Lin28a in the hippocampal NPCs is related to adult neurogenesis, we then knocked out Lin28a from Nestin ${ }^{+}$NPCs in Nestin-Cre ${ }^{\text {ERT2 }}:$ :Lin28a ${ }^{\text {flox/flox }}$ mice by tamoxifen (TAM) treatment, and examined the neurogenesis in the DG of these mice four weeks later (Figure 2C). We found loss of Lin28a from Nestin ${ }^{+}$NPCs significantly decreased the number of cells expressing proliferation marker minichromosome maintenance complex component 2 (MCM2) (Figure 2D), as indicated by the density of $\mathrm{MCM}^{+}$cells in the SGZ and the percentage of $\mathrm{MCM}^{+}$cells in total $\mathrm{DAPI}^{+}$cells in the GCL (Figure $2 \mathrm{E}$ and F). Similarly, DCX-positive cells significantly decreased in the DG of the TAM-treated animals, compared to the mice treated with vehicle (Veh) (Figure 2G-I). To further verify whether loss of Lin28a in NPCs indeed results in fewer adult-born neurons, we treated and Nestin-Cre ${ }^{\text {ERT2 }}::$ Lin28a ${ }^{\text {flox/flox }}::$ Ai14 $\left(\right.$ Lin28a ${ }^{\text {f/f }}$ ) mice and Nestin-Cre ${ }^{\mathrm{ERT} 2}::$ Lin28a ${ }^{+/+}:$Ai14 (Ctrl) mice of the same age and genetic background with tamoxifen, and examined the number of dTomato-labeled cells in the DG six weeks later (Figure 2J). We found that lack of Lin28a indeed decreased the density and the proportion of dTomato ${ }^{+}$cells in the DG of Lin28a ${ }^{\mathrm{f} / \mathrm{f}}$ mice, compared with $\mathrm{Ctrl}$ mice (Figure $2 \mathrm{~K}-\mathrm{M}$ ). These data suggest that Lin28a is necessary for the generation of new neurons from adult hippocampal NPCs, whereas loss of Lin28a leads to decreased neurogenesis in the adult DG.

We then tested Nestin-Cre ${ }^{\text {ERT2 }}:$ :Lin28 ${ }^{\text {flox/flox }}$ mice for pattern separation, six weeks after Veh or TAM treatment (Figure $2 \mathrm{~N}$ ). In consistence with the decreased hippocampal neurogenesis, TAM-treated mice 
discriminated the two similar contexts A and B later than Veh-treated mice did (Figure 2O), mimicking the decreased ability of pattern separation in aging animals.

In addition, similar to the behavioral phenotypes seen in the aging animals, the TAM-treated Nestin$\mathrm{Cre}^{\text {ERT2 }}:$ :Lin28a ${ }^{\text {flox/flox }}$ mice didn't show significant difference in single-trial contextual fear memory test (Figure EV3A and B), or novel object recognition (Figure EV3C - E). However, TAM-treated mice showed impaired novel location recognition (Figure EV3F - H).

These results suggest that the decreased Lin28a level in hippocampal NPCs may contribute to the decline of neurogenesis and the ability of pattern separation in the aging animals.

\section{Overexpression of Lin28a increases the progenies of NPCs in the adult DG}

Next, to investigate how Lin28a regulates neural progenitors in the adult brain, we generated FLEX retroviral vectors that express GFP (Ctrl) or GFP-p2A-Lin28a (Lin28a-OE) (Figure 3A). We injected diluted virus into the DG of adult Nestin-Cre mice, so that GFP or Lin28a could be expressed upon the presence of Cre recombinase in individual dividing Nestin ${ }^{+}$NPCs and their progenies in a sparse distribution (Figure 3B). With this method, we were able to trace the progenies from individual active neural stem cells, as previously described (Kirschen et al., 2017). We examined GFP labeled cell clusters 7 days after viral injection, and found that the overexpression of Lin28a significantly increased the size of cell clusters generated from individual NPCs, from an average of $1.77 \pm 0.11$ to $3.23 \pm 0.26$ cells per cluster (Figure $3 \mathrm{C}-\mathrm{E}$ ).

To confirm this result and avoid possible mixture of adjacently-labeled cell clusters, we designed a FLEX m/n/cXFP retroviral reporter system that expresses membranous RFP (mRFP), nuclear CFP (nCFP) or cytosolic GFP (cGFP) in random combinations depending on Cre recombinase expression (Figure 3F). Seven days post viral injection, we analyzed labeled cell clusters in both Ctrl and Lin28a-OE groups (Figure 3G). Consistent with the data shown in Figure 3D and E, cells overexpressing Lin28a (containing cGFP) exhibited increased cluster size of $2.73 \pm 0.18$ cells, compared to $1.48 \pm 0.08$ cells in Ctrl clusters (Figure $3 \mathrm{H}$ and I), 
confirming that the overexpression of Lin28a indeed increased the number of cells generated from each individual NPC.

\section{The effect of Lin28a overexpression on cell cycle, survival and differentiation}

To investigate how Lin28a regulate the number of progenies of NPCs, we next tested whether Lin28a could regulate the cell cycle of hippocampal NPCs. Two days after the injection of FLEX retroviruses (Figure 3A) into the DG of Nestin-Cre mice, we started treating the animals with BrdU every 6 hours for 5 times. Seven days after viral injection, we perfused the animals and stained the brain sections for BrdU and MCM2 (Figure 4A). By this method, we could label dividing Nestin ${ }^{+}$NPCs with GFP at their first division, and then mark their second division with BrdU if the mitosis happened during the window of BrdU administration, while a third division could be detected by MCM2 staining (Figure 4B). We found overexpressing Lin28a in NPCs significantly increased the percentage of $\mathrm{GFP}^{+} \mathrm{BrdU}^{+}$and $\mathrm{GFP}^{+} \mathrm{BrdU}^{+} \mathrm{MCM}^{+}$cells in GFP-labeled cells (Figure 4C), indicating that the overexpression of Lin28a enlarges the size of cell clusters via increasing the number of cell cycles of NPCs.

Next, to test whether the change in the survival of newborn cells could also count for the increase of cluster size, we stained for activated caspase-3 (aCas-3) four days after retroviral injection (Figure 4D). We found colocalization of aCas-3 with GFP-labeled newborn cells did not show significant difference between cells overexpressing Lin28a and Ctrl cells expressing GFP only (Figure 4E).

To further find out whether Lin28a controls the differentiation of newborn cells, we overexpressed Lin28a in Nestin ${ }^{+}$NPCs and quantified proportion of $\mathrm{DCX}^{+}$newborn neurons (Figure 4F), s100 $\beta^{+}$astrocytes (Figure 4G) and GFAP ${ }^{+}$s100 $\beta^{-}$neural stem/progenitor cells (Figure 4H) in GFP-labeled newborn cells, seven days after viral injection. We found the overexpression of Lin28a did not significantly change the proportion of $\mathrm{GFAP}^{+} \mathrm{s} 100 \beta^{-}$cells, but slightly increased the proportion of $\mathrm{DCX}^{+}$cells and decreased the percentage of 
s100 $\beta^{+}$cells (Figure 4I). This result suggests that Lin28a may potentially support the newborn cells to differentiate towards neuronal lineage, and inhibit the differentiation of newborn cells towards astrocytes.

\section{Lin28a regulates the development and functional integration of new neurons in the adult DG}

Since Lin28a is also detected in DGCs, we wondered whether Lin28a regulates the development and functional integration of the newborn neurons. We then labeled the newborn neurons in the DG of adult C57BL/6 mice using retroviral vectors expressing GFP (Ctrl) or GFP-p2A-Lin28a (Lin28a-OE), and examined the morphological development of labeled newborn neurons at 1, 2, 3 and 4 weeks post retroviral injection (wpi) (Figure 5A). Our data showed that neurons overexpressing Lin28a exhibited significantly more complex dendrites (Figure 5B), longer total dendritic length (Figure 5C) and more dendritic branches at all developmental stages (Figure 5D), suggesting that the overexpression of Lin28a facilitates the development of newborn neurons.

To test whether Lin28a is necessary for the development of newborn neurons, we injected retrovirus expressing GFP-p2A-Cre into the DG of Lin28a ${ }^{\text {flox/flox }}$ mice to knockout Lin28a from labeled newborn neurons $\left(\operatorname{Lin} 28 \mathrm{a}^{\mathrm{f} / \mathrm{f}}\right.$ ), while Ctrl cells were labeled by retrovirus expressing GFP only (Figure 5E). At 3 wpi, we found Lin28 $\mathrm{a}^{\mathrm{f} / \mathrm{f}}$ newborn neurons showed less complex dendrites (Figure 5F), shorter dendritic length (Figure 5G) and less dendritic arborizations when compared with Ctrl cells (Figure 5H).

Since the third week is the critical time period during which newborn DGCs form synaptic connections with afferent glutamatergic projections (Kumamoto et al., 2012), we further analyzed the dendritic spines of the newborn neurons at 3 wpi. We found that Lin28a-OE newborn neurons exhibited greatly increased spine density, while Lin28a ${ }^{\mathrm{f} / \mathrm{f}}$ newborn neurons showed significantly less dendritic spines than Ctrl cells expressing GFP only (Figure 5I and J). To verify whether Lin28a regulates the functional synaptic integration of newborn neurons, we then did whole-cell patch-clamp recordings on labeled newborn neurons and recorded the miniature excitatory postsynaptic currents (mEPSCs) at 3 wpi. We found that the overexpression of 
Lin28a in newborn neurons significantly increased mEPSCs frequency without affecting mEPSCs amplitude

(Figure 5K - M), whereas knocking out Lin28a from newborn neurons significantly reduced mEPSCs frequency but not amplitude (Figure $5 \mathrm{~N}-\mathrm{R}$ ). Thus, these data suggest that Lin28a facilitated, whereas loss of Lin28a hindered, the development and functional synaptic integration of newborn neurons in the adult brain.

\section{Lin28a is involved in Wnt-mediated regulation of neurogenesis}

Given Wnt signaling regulates age-dependent decline of neurogenesis in the adult hippocampus (Seib et al., 2013), and $\beta$-catenin promotes the expression of Lin28a in a variety of cell types (Cai et al., 2013; Yao et al., 2016), we wondered whether Lin28a is the intracellular mediator through which Wnt signaling regulates adult hippocampal neurogenesis. We injected lentivirus expressing Wnt3a, a Wnt agonist expressed in hippocampal neurogenic niche (Kuwabara et al., 2009; Lie et al., 2005), into the DG of adult mice (Figure $6 \mathrm{~A}-\mathrm{C}$ ). We found an increased level of $\beta$-catenin in the DG (Figure 6D and E), suggesting an enhanced canonical Wnt signaling. Using RNAscope, we found the amount of Lin28a mRNA in Sox2-expressing NPCs significantly increased in animals injected with Wnt3a-expressing virus, compared to those injected with control virus expressing GFP only (Figure 6F and G). These data suggest that the expression of Lin28a in NPCs was increased by enhanced Wnt signaling.

To further confirm whether upregulation of $\beta$-catenin could directly enhance the expression of Lin28a in NPCs, we constructed a FLEX lentiviral vector expressing mouse Ctnnb1, which codes the protein catenin beta 1 (Figure $6 \mathrm{H})$. We injected the virus into the DG of Nestin-Cre mice, and performed RNAscope a week later. We found overexpressing Ctnnb1 in Nestin ${ }^{+}$NPCs indeed increased the mRNA level of Lin28a in these labeled cells (Figure 6I and J).

Next, we injected lentivirus expressing Wnt3a into the DG of Nestin-Cre ${ }^{\text {ERT2 }}:$ Lin $28 a^{\text {flox/flox }}$ mice, one week after TAM administration (Figure 7A), by which Lin28a was knocked out from Nestin ${ }^{+}$NPCs 
$\left(\operatorname{Lin} 28 \mathrm{a}^{\mathrm{f} / \mathrm{f}}\right)$. Four more weeks later, we found Wnt3a lentivirus significantly increased DCX ${ }^{+}$cells in the DG of $\mathrm{Cre}^{-/-}$littermates $(\mathrm{Ctrl})$. In contrast, upregulation of Wnt3a was not able to increase the number of DCX cells in the DG of Lin28a $\mathrm{a}^{\mathrm{f} / \mathrm{f}}$ animals (Figure $7 \mathrm{~B}-\mathrm{D}$ ). To confirm this finding, we next used Nestin$\operatorname{Cre}^{\text {ERT2 }}::$ Lin28 ${ }^{\text {flox/flox }}::$ Ai14 mice to label the progenies of the NPCs, from which Lin28a was knocked out $\left(\operatorname{Lin} 28 \mathrm{a}^{\mathrm{f} / \mathrm{f}}\right)$; Nestin-Cre ${ }^{\mathrm{ERT} 2}:: \operatorname{Lin} 28 \mathrm{a}^{+/+}::$Ai14 mice of the same age were used as control (Ctrl) (Figure 7E). Consistently, we found Wnt3a lentivirus significantly increased dTomato ${ }^{+}$cells in the DG of control mice.

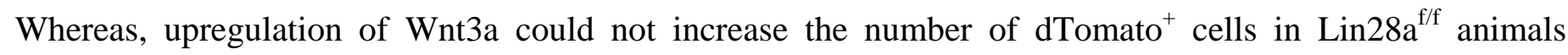
(Figure $7 \mathrm{~F}-\mathrm{H}$ ). These results indicate that Lin28a in NPCs was necessary for the regulation of adult hippocampal neurogenesis by niche Wnt signaling.

Previous studies have shown that the deficiency in Wnt signaling results in decreased neurogenesis in the adult hippocampus (Jang et al., 2013; Seib et al., 2013). To test whether the overexpression of Lin28a is sufficient to recover impaired neurogenesis in Wnt-deficient hippocampus, we constructed a lentiviral vector expressing a dominant negative Wnt1 (dnWnt1) (Figure 7I), which has been shown to inhibit Wnt signaling and decrease neurogenesis (Choi et al., 2018; Lie et al., 2005). We also constructed another lentiviral vector that contains a FLEX GFP-p2A-Lin28a, so that we could overexpress Lin28a in the presence of Cre recombinase (Figure 7I). We injected the lentivirus expressing dnWnt1-dTomato or dTomato only into the DG of Nestin-Cre mice, and infused lentivirus expressing FLEX GFP-p2A-Lin28a two weeks later to overexpress Lin28a in the Nestin ${ }^{+}$NPCs (using lentivirus expressing FLEX-GFP as Ctrl). Four more weeks later, we perfused the mice and quantified the number of $\mathrm{DCX}^{+}$cells in the $\mathrm{DG}$ of these animals (Figure $7 \mathrm{~J}$ ). We found expression of dnWnt1 indeed decreased the number of $\mathrm{DCX}^{+}$newborn neurons in the DG, whereas upregulation of Lin28a in NPCs increased the number of $\mathrm{DCX}^{+}$cells in dTomato group and recovered the number of $\mathrm{DCX}^{+}$cells in the dnWnt1 group (Figure $7 \mathrm{~K}$ and $\mathrm{L}$ ). These data suggest that overexpressing Lin28a in NPCs was sufficient to restore neurogenesis in Wnt-deficient hippocampal neurogenic niche. 


\section{Overexpression of Lin28a in NPCs restores neurogenesis in the aging hippocampus and enhances pattern}

\section{separation}

Since the overexpression of Lin28a could upregulate the proliferation of NPCs and facilitate the integration of newborn cells, we wondered whether overexpression of Lin28a in NPCs could enhance pattern separation by increasing hippocampal neurogenesis. We injected Cre-dependent lentivirus expressing FLEX GFP-p2A-Lin28a (Lin28a-OE) into the DG of young adult Nestin-Cre mice (2mo) to overexpress Lin28a in a large population of existing NPCs in SGZ, while virus expressing GFP was use as control (Ctrl) (Figure 8A and B). Six weeks later, the mice showed significantly increased $\mathrm{DCX}^{+}$newborn neurons when Lin28a is specifically overexpressed in Nestin ${ }^{+}$NPCs and their progenies, compared to Ctrl mice (Figure 8C and D). Lin28a-OE mice started to show discrimination between contexts $\mathrm{A}$ and $\mathrm{B}$ in training session 2 , while $\mathrm{Ctrl}$ mice started to show discrimination in session 4 (Figure 8E), suggesting Lin28a-OE mice exhibited enhanced ability of pattern separation.

To test whether overexpressing Lin28a could enhance neurogenesis in aging animal and improve their ability of pattern separation, we injected the above-mentioned lentiviruses into the DG of aging Nestin-Cre mice (12 mo) (Figure 8F). Six weeks later, we found that overexpression of Lin28a in the NPCs in aging mice showed increased number of $\mathrm{DCX}^{+}$newborn neurons in the $\mathrm{DG}$, compared to Ctrl mice (Figure $8 \mathrm{G}$ and H). Consistent with the data shown in Figure 2B, the aging mice in the Ctrl group exhibited poor contextual discrimination, as the freezing time of these animals in contexts A and B did not show difference till session 6 (Figure 8I). Interestingly, when Lin28a was overexpressed in the remaining Nestin ${ }^{+} \mathrm{NPCs}_{\text {in }}$ the DG of aging mice, the animals started to discriminate contexts $\mathrm{A}$ and $\mathrm{B}$ in session 4 , much sooner than the $\mathrm{Ctrl}$ group, suggesting a restored ability of pattern separation (Figure 8I).

These results demonstrate that increasing the expression of Lin28a in NPCs promoted neurogenesis, thus leading to enhanced pattern separation. Moreover, overexpressing Lin28a in hippocampal NPCs in aging mice could rescue their weakened ability of pattern separation by increasing neurogenesis in the DG. 


\section{Discussion}

\section{Lin28a regulates neurogenesis in the adult hippocampus}

RNA binding protein Lin28 has been shown to play important roles in a variety of biological processes, through let-7-dependent and independent pathways (Shyh-Chang and Daley, 2013). During the early development of the nervous system, Lin28 is highly expressed in neural stem/progenitor cells, whereas its expression level drops sharply as neuronal differentiation proceeds (Yang et al., 2015). Interestingly, our results showed that Lin28a remained existent in NPCs and DGCs in the adult hippocampus, suggesting its potential biological role in these cells.

Loss of Lin28a in hippocampal NPCs decreased neurogenesis, whereas the overexpression of Lin28a increased neurogenesis, by enhancing the proliferation of NPCs. This result is in agreement with previous study showing that, Lin28a knockout in the developing brain results in microcephaly whereas overexpressing Lin28a in Nestin ${ }^{+}$NPCs leads to enlarged brain size (Yang et al., 2015). Our results also showed that, the overexpression of Lin28a in NPCs enhanced neurogenesis mainly by increasing the number of cell cycles, but not by altering the survival of newborn cells. Further analysis showed that overexpression of Lin28a decreased the proportion of newborn cell differentiated towards astrocytes, in consistence with a previous report showing that Lin28 suppresses glial fate of NPCs in vitro (Balzer et al., 2010).

In addition, we found Lin28a was not only expressed in NPCs, but also in DG neurons. Loss of Lin28a in newborn neurons inhibited, while the overexpression of Lin28a facilitated, the development and functional integration of newborn neurons, suggesting Lin28a not only regulates the proliferation of NPCs, but also controls the growth of newborn neurons in the adult hippocampus.

However, opposite to our results, a recent study showed that overexpression of Lin28 in the SVZ NPCs decreased the number of new neurons in the olfactory bulb of postnatal mice (Romer-Seibert et al., 2019). This result may be attributed to that the overexpression of Lin28 repressed let-7, which is important for the 
migration of neuroblasts (Petri et al., 2017), thus decreasing the number of new neurons arriving in the olfactory bulb. Although it is reported that short-distance lateral dispersion is required for the integration of newborn neurons in the DG (Wang et al., 2019), we did not observe developmental or integrating defects in newborn neurons when Lin28a is overexpressed.

It has been shown that Lin28a and Lin28b are both required and play overlapping functions in regulating NPC proliferation and brain development during early development (Yang et al., 2015). We did not detect Lin28b expression in the adult DG using RNAscope, either in Nestin ${ }^{+}$NPCs or in Prox $1^{+}$DGCs, suggesting differential expression of Lin28a and Lin28b in the adult brain. It is reported that Lin $28 \mathrm{~b}$ knockout mice exhibit no detectable phenotypes (Shinoda et al., 2013), whereas loss of Lin28a results in reduced brain size at birth (Yang et al., 2015). These suggest that Lin28a serves as the dominant Lin28 homolog regulating neurogenesis in both developing and adult brains. Moreover, it has been reported that the expression of Lin28a, but not Lin28b, is regulated by Wnt- $\beta$-catenin signaling (Cai et al., 2013), suggesting Lin28a may play more important roles rather than Lin28b in regulating neurogenesis in the presence of extracellular Wnt signals.

\section{Decrease of Lin28a expression is involved in aging-associated decline of neurogenesis}

Hippocampal neurogenesis decreases in mammals with aging (Kuhn et al., 1996; Spalding et al., 2013), associated with and contributing to cognitive declines in aging (Lee et al., 2012; Seib et al., 2013). Multiple pathways have been revealed to contribute to age-related decline of adult neurogenesis (Meyers et al., 2016; Miranda et al., 2012; Seib et al., 2013; Yang et al., 2017; Yousef et al., 2015). Wnt signaling pathway has been shown to be of essential importance for the regulation of multiple stages of adult hippocampal neurogenesis (Lie et al., 2005; Schafer et al., 2015). Both existing in the neurogenic niche and changing with aging or activity, Wnt ligands promote (Lie et al., 2005; Song et al., 2002), while Wnt antagonists inhibit 
neurogenesis (Jang et al., 2013; Seib et al., 2013), thus contributing to aging-associated decline of neurogenesis.

Interestingly, we observed a decreased expression of Lin28a in the hippocampal NPCs with aging, coincident with the increased Wnt antagonist Dkk1 in the niche (Seib et al., 2013). Furthermore, we found the upregulation of niche Wnt3a or overexpression of Ctnnb1 in the NPCs increased the expression of Lin28a in hippocampal NPCs, in consistence with a previous study that Wnt- $\beta$-catenin signaling regulates the expression of Lin28a, by direct binding of $\beta$-catenin to Lin28a promoter (Cai et al., 2013). A recent study also showed that Wnt- $\beta$-catenin signaling regulates the proliferation and neurogenic potential of retinal müller glia cells via Lin28/let-7 pathway (Yao et al., 2016). These clues suggest that Lin28a serves as a downstream mechanism underlying the regulation of neurogenesis by niche Wnt signals.

In the adult hippocampus, our results showed that Lin28a regulated the proliferation of NPCs and the development of new neurons, consistent with the regulation of neurogenesis by Wnt signals (Jang et al., 2013; Lie et al., 2005; Seib et al., 2013). Especially, loss of Lin28a from NPCs reduced neurogenesis and inhibited the development of new neurons, mimicking the effects of increased Wnt antagonists in the neurogenic niche (Jang et al., 2013; Seib et al., 2013). Thus, in the aging brain, with the increasing niche Wnt antagonists (Seib et al., 2013), decreased Lin28a expression in NPCs contributes to the declining neurogenesis.

Importantly, lacking of Lin28a in NPCs blocked the enhanced neurogenesis by Wnt3a, suggesting that Lin28a is essential for NPCs to respond to local Wnt signals in the adult hippocampal neurogenic niche. On the other hand, upregulation of Wnt antagonist dnWnt1 in the neurogenic niche, which has been shown to block Wnt signaling (Choi et al., 2018; Lie et al., 2005), significantly decreased adult neurogenesis in the DG; whereas the overexpression of Lin28a in NPCs could rescue neurogenesis in this Wnt-deficient microenvironment. Consistently, in aging animals, the overexpression of Lin28a in the remaining NPCs could at least partially restore hippocampal neurogenesis. 
It has been shown that young adult-born neurons in the DG are essential for pattern separation (Nakashiba et al., 2012; Sahay et al., 2011a). In human, pattern separation undergoes an age-related decline in performance, correlating with the decay of neurogenesis in the DG (Stark et al., 2010). Knocking out Lin28a from NPCs resulted in decreased neurogenesis and impaired pattern separation, recapitulating the phenotype in aging animals. Overexpression of Lin28a in NPCs could increase neurogenesis, and thus enhance pattern separation in both young and aging mice. These results suggest that pattern separation is susceptible to the changes in hippocampal neurogenesis, which is regulated by Lin28a level in hippocampal NPCs.

Taken together, our study revealed that Lin28a regulates neurogenesis in response to Wnt signals in the adult hippocampus in vivo, suggesting that Lin28a acts as one important link between niche Wnt ligands/antagonist and neurogenesis in the aging brain. As other target genes of Wnt- $\beta$-catenin signaling through TCF/LEF, such as Neurodl and Proxl, have also been shown to regulate adult neurogenesis (Gao et al., 2009; Kuwabara et al., 2009; Lavado et al., 2010; Lie et al., 2005; Miranda et al., 2012), further studies will be needed for understanding possible interactions between these molecules in NPCs.

\section{Materials and Methods}

\section{Animals}

All procedures were approved by the Animal Care and Use Committees at the Zhejiang University School of Medicine, and conducted in accordance with the policies of institutional guidelines on the care and use of laboratory animals.

All mice were bred in the animal facility at the Zhejiang University School of Medicine, and maintained at a $12 \mathrm{hr}$ light/dark cycle. Mice were group housed (3-4 per cage) in transparent plastic cages $(35 \times 15 \times 20$ $\mathrm{cm}$ ), with free access to normal food and water unless otherwise specified. Males and females were equally used for experiments. 
Lin28a ${ }^{\text {flox/flox }}$ mice (Stock No. 023913), Nestin-Cre mice (Stock No. 003771), Nestin-Cre ${ }^{\text {ERT2 }}$ mice

(Stock No. 016261) and Ai14 reporter line (Stock No. 007914) were from Jackson Labs; Nestin-GFP mice (Stock No. RBRC06355) were from RIKEN.

\section{Tamoxifen administration}

Tamoxifen (TAM) (Sigma, T5648) was dissolved in vegetable oil containing $0.1 \%$ absolute ethanol to a concentration of $100 \mathrm{mg} / \mathrm{ml}$.

For conditional knocking out Lin28a from Nestin ${ }^{+}$NPCs in Nestin-Cre ${ }^{\text {ERT2 }}:$ Lin $28 \mathrm{a}^{\text {flox/flox }}$ mice, or labeling and knocking out Lin28a from Nestin ${ }^{+}$NPCs in Nestin-Cre ${ }^{\text {ERT2 }}::$ Lin28 ${ }^{\text {flox/flox }}::$ Ai14 mice, TAM was administered i.p. at the dose of $160 \mathrm{mg} / \mathrm{kg}$ every three days for five times.

\section{Construction of viral vectors}

\section{1) Lin28a retroviral and lentiviral vectors}

Mouse Lin28a mRNA CDS sequence was obtained from GenBank (NCBI Reference Sequence: NM_145833.1, CCDS18761.1), synthesized and inserted into a pUX-GFP retroviral plasmid vector to make pUX-GFP-p2A-Lin28a. pUX-GFP was used as control vector.

GFP-p2A-Lin28a fragment was then subcloned and inserted in a reversed direction into a pUX-FLEX retroviral plasmid vector to make a Cre-dependent retroviral plasmid vector pUX-FLEX-GFP-p2A-Lin28a. pUX-FLEX-GFP was used as control vector.

GFP-p2A-Lin28a fragment was then subcloned and inserted in a reversed direction into a pHage-FLEX lentiviral plasmid vector to make a Cre-dependent lentiviral plasmid vector pHage-FLEX-GFP-p2A-Lin28a. pHage-FLEX-GFP was used as control vector.

\section{2) Truncated Lin28a (tLin28a) and mutant Lin28a (mutLin28a) retroviral vectors}


A truncated Lin28a sequence (1 to 408 of Lin28a cDNA sequence) was subcloned into pUX-GFP plasmid vector to make pUX-GFP-p2A-tLin28a. GFP-p2A-tLin28a fragment was then cut and inserted in a reversed direction into a pUX-FLEX retroviral plasmid vector to make pUX-FLEX-GFP-p2A-tLin28a.

Lin28a DNA sequence with two point mutations (to change H147 and H169 to alanines in the protein) was synthesized and subcloned into pUX-GFP plasmid vector to make pUX-GFP-p2A-mutLin28a. GFPp2A-mutLin28a fragment was then cut and inserted in a reversed direction into a pUX-FLEX retroviral plasmid vector to make pUX-FLEX-GFP-p2A-mutLin28a.

\section{3) Wnt3a lentiviral vector}

Mouse Wnt3a mRNA CDS sequence was obtained from GenBank (NCBI Reference Sequence: NM_009522.2, CCDS 24766.1), synthesized and then subcloned and inserted in a reversed direction into a pHage-GFP lentiviral plasmid vector to make a lentiviral plasmid vector pHage-Wnt3a-p2AGFP.

\section{4) dnWnt1 lentiviral vector}

A dominant negative mouse Wnt1 (dnWnt1) sequence, as previously described (Hoppler et al., 1996), was synthesized and then subcloned and inserted in a reversed direction into a pHage-GFP lentiviral plasmid vector to make a lentiviral plasmid vector pHage-dnWnt1-p2A-dTomato.

\section{5) Ctnnb1 lentiviral vector}

Mouse Ctnnb1 mRNA CDS sequence was obtained from GenBank (NCBI Reference Sequence: NM_007614.3, CCDS23630.1), synthesized and then subcloned and inserted in a reversed direction into a pHage-FLEX-GFP lentiviral plasmid vector to make a lentiviral plasmid vector pHageFLEX-Ctnnb1-p2A-GFP.

\section{6) $m / c / n X F P$ retroviral vectors}


Membrane RFP (mRFP) and nucleus CFP (nCFP) sequences were inserted in a reversed direction into pUX-FLEX retroviral vector to make the pUX-FLEX-mRFP and pUX-FLEX-nCFP vectors, respectively. Above mentioned pUX-FLEX-GFP vector was used as pUX-FLEX-cGFP (cytosol GFP).

\section{Virus production:}

As previously described ( $\mathrm{Gu}$ et al., 2012), each retroviral or lentiviral backbone plasmid was cotransfected to $293 \mathrm{~T}$ cells with helper plasmids for retrovirus or lentivirus using Lipofectamine 2000 (Invitrogen). Culture medium was collected, then virus was purified and concentrated by ultracentrifugation.

\section{Virus injection:}

Stereotactic viral injections were performed in accordance with the Guidelines by Zhejiang University Animal Care and Use Committees. As previously described (Gu et al., 2012), mice were anesthetized using isoflurane and mounted on a stereotaxic machine. Viral particles were then injected using a $1 \mu l$ Hamilton syringe bilaterally into the DG (coordinates: $2.0 \mathrm{~mm}$ caudal to bregma, $1.6 \mathrm{~mm}$ lateral from the midline and $2.5 \mathrm{~mm}$ ventral; $3.0 \mathrm{~mm}$ caudal to bregma, $2.6 \mathrm{~mm}$ lateral from the midline and $3.2 \mathrm{~mm}$ ventral). Mice were then returned to their home cages after waking up, and then housed under standard conditions.

\section{Immunostaining, confocal imaging and image analysis}

As previously described ( $\mathrm{Gu}$ et al., 2012), mice were deeply anesthetized and perfused transcardially with PBS and then 4\% PFA. Brains were removed, fixed overnight in PFA and then transferred to a $30 \%$ $(\mathrm{w} / \mathrm{v})$ sucrose solution and stored at $4{ }^{\circ} \mathrm{C}$. Brains were sectioned into $50-\mu \mathrm{m}$ coronal sections covering the full anterior-posterior extent of the hippocampus. Regular immunohistochemistry was performed using primary antibodies to Lin28a (Cell Signaling Technology, 8641, 1:50), Lin28 (Abcam, ab63740, 1:50), Prox1 (Abcam, ab199359, 1:500), NeuN (Abcam, ab104224, 1:1000), Iba-1(Wako, 019-19741, 1:1000), 
GFAP(Abcam, ab4674, 1:1000), s100ß (Abcam, ab52642, 1:1000), MCM2 (Cell Signaling Technology, 4007, 1:500), DCX (Cell Signaling Technology, 4604, 1:1000) or GFP (Abcam, ab12218, 1:3000), overnight at $4{ }^{\circ} \mathrm{C}$, followed by incubation with secondary antibodies (Cy2-conjugated donkey antibody to chicken (Jackson Immune, 703-225-155, 1:1000), Cy3-conjugated donkey antibody to rabbit (Jackson Immune, 711165-152, 1:1000), Cy5-conjugated donkey antibody to rabbit (Jackson Immune, 711-175-152, 1:1000) or Cy5-conjugated donkey antibody to chicken (Jackson Immune, 703-175-155, 1:1000) for 2 hours at room temperature $\left(25^{\circ} \mathrm{C}\right)$, in the presence of $2 \%$ donkey serum, $1 \%$ bovine serum albumin and $0.2 \%(\mathrm{w} / \mathrm{v})$ Triton X-100. Sections were mounted on slides with Fluoromount-G anti-fade medium containing DAPI (SouthernBiotech). Images of $\mathrm{z}$ series stacks were taken on an Olympus FV3000 confocal microscope. Images were analyzed using Image J or Imaris software.

For analyzing the neurogenesis in the $\mathrm{DG}$, the density and percentage of $\mathrm{MCM}^{+}, \mathrm{DCX}^{+}$or dTomatolabeled cells were calculated and analyzed. For calculating the density of cells, we flattened the SGZ and projected the $\mathrm{MCM}^{+}, \mathrm{DCX}^{+}$or $\mathrm{dTomato}^{+}$cell body to the plane of the flattened SGZ, and the density of each type of cell was calculated as number of $\mathrm{MCM}^{+}, \mathrm{DCX}^{+}$cells per $100 \times 100 \mu \mathrm{m}^{2}$ area of the flattened SGZ. The percentage of $\mathrm{MCM}^{+}, \mathrm{DCX}^{+}$or $\mathrm{dTomato}^{+}$cells in the dentate gyrus was calculated as the proportion of each types of cells in the total number of cells $\left(\mathrm{DAPI}^{+}\right)$in the cell body layer of the analyzed DG region. The cell counting covered the whole dentate gyrus in each section, and sections from dorsal through ventral part of the hippocampus were imaged, analyzed, and then averaged for each animal.

\section{Clonal labeling and analysis}

Engineered self-inactivating murine oncoretroviruses were used to deliver genes of interest specifically to proliferating cells and their progeny (Ge et al., 2006; van Praag et al., 2002). To label clusters of newborn cells generated from individual NPCs, we injected FLEX retrovirus expressing GFP or overexpressing Lin28a into the DG of Nestin-Cre mice, thus resulting in sparse labeling of progenies of individual dividing 
Nestin $^{+}$neural stem cells, as we previous described (Kirschen et al., 2017). Brains were sliced into $60 \mu \mathrm{m}$ sections and GFP was enhanced by staining. Sections were then mounted on slides with Fluoromount-G antifade medium with DAPI. For analysis, we only selected isolated cell clusters, and cells within $100 \mu \mathrm{m}$ distance were considered belonging to the same cell cluster.

To avoid mixture of adjacent cell clusters, we used a combination of FLEX m/n/cXFP retroviral vectors to label different cell clusters with different combination of colors. $\mathrm{m} / \mathrm{n} / \mathrm{cXFP}$ retroviruses were mixed and injected into the DG of Nestin-Cre mice, and the animals were perfused 7 days after viral injection. Brains were sliced into $60 \mu \mathrm{m}$ sections, which were then mounted on slides with Fluoromount-G anti-fade medium without DAPI (SouthernBiotech). For analysis, only adjacent labeled cells with the same combination of colors were considered belonging to the same cell cluster. For Lin28a, tLin28a or mutLin28a groups, we mixed pUX-FLEX-GFP-p2A-Lin28a, pUX-FLEX-GFP-p2A-tLin28a or pUX-FLEX-GFP-p2A-mutLin28a with pUX-FLEX-mRFP and pUX-FLEX-nCFP retroviruses for combinations. Only cells expressing GFP were considered as overexpressing Lin28a, tLin28a or mutLin28a.

\section{Labeling the division of NPCs}

Cre-dependent retrovirus (pUX-FLEX-GFP or pUX-FLEX-GFP-p2A-Lin28a) was injected into the DG of adult Nestin-Cre mice. 48 hours after viral injection, BrdU (Sigma, B5002) was administered (i.p., $100 \mathrm{mg} / \mathrm{kg}$ ) every 6 hours for 5 times. Seven days after viral injection, mice were perfused and brain sections were stained using primary antibodies to GFP (Abcam, ab12218, 1:3000), BrdU (Abcam, Ab6326, 1:1000) and MCM2 (Cell Signaling Technology, 4007, 1:500) over night at $4{ }^{\circ} \mathrm{C}$, followed by incubation with secondary antibodies. Images of GFP-labeled cells were taken on an Olympus FV3000 confocal microscope, and were analyzed for colocalization of GFP, BrdU and MCM2, using Image J or Imaris.

\section{Labeling apoptotic newborn cells}


Retrovirus expressing GFP (Ctrl) or GFP-p2A-Lin28a (Lin28a-OE) was injected into the DG of adult C57 mice. 3 days after viral injection, mice were perfused and brain sections were stained using primary antibodies to GFP (Abcam, ab12218, 1:3000) and aCas-3 (Abcam, ab13847, 1:200) over night at $4{ }^{\circ} \mathrm{C}$, followed by incubation with secondary antibodies. Images of GFP-labeled cells were taken on an Olympus FV3000 confocal microscope, and colocalization of GFP and aCas-3 were analyzed for using Image J or Imaris.

\section{RNAscope in situ hybridization}

Brain slices $(14 \mu \mathrm{m})$ were prepared as described above. In situ hybridization was performed using RNAscope multiplex fluorescent reagent kit (Advanced Cell Diagnostics) according to manufacturer's standard instructions. Ethanol was used for gradient dehydration of the sections. Probes were designed by ACDbio (probes : Mm-Lin28a, 437121; Mm-Sox2-C3, 401041-C3; Neg-ctrl, 320871; Pos-ctrl, 320881).

Additional immunostaining was done following the detection of mRNA with standard protocols as described above. Images were obtained using an Olympus FV3000 confocal microscope. For the quantification of mRNA expression level in single cells, the number of dots in each cell of interest were counted using ImageJ software. To minimized the influence of non-specific signals, RNAscope using the negative control probe (Neg-ctrl) was also performed at the same time on the same sets of samples, and the average number of dots in each cell obtained using Neg-ctrl probes was subtracted from the number of dots obtained using target probes.

\section{Western blot analysis}

To detect the Lin28a and other protein levels in the DG, mice were anesthetized with isoflurane (1.5$3.0 \%)$ and the brain was removed and cut into acute slices $(300 \mu \mathrm{m})$ in cold PBS. The DG was dissected and collected, then homogenized and centrifuged at 12000 r.p.m. at $4^{\circ} \mathrm{C}$ for 10 minutes. Each sample contained 
DG tissues from 3 animals. Protein concentration was detected by the BCA Protein Assay Kit (Beyotime, P0011). Samples were diluted in $5 \times$ loading buffer and were boiled at $100^{\circ} \mathrm{C}$ for $10 \mathrm{~min}$. Proteins were then separated in $12 \%$ gel by SDS-PAGE and transferred to PVDF membranes (Merck Millipore, ISEQ00010), which were then block with $5 \%$ milk in TBS-T buffer at room temperature for 1 hour. Membranes were incubated with primary antibodies to Lin28a (Cell Signaling Technology, 8641, 1:500), rabbit-anti-Lin28 (Abcam, ab63740, 1:500) or rabbit- $\beta$-catenin (Cell Signaling, 8480, 1:1000) at $4^{\circ} \mathrm{C}$ overnight. Membranes were then incubated with horseradish peroxidase-conjugated goat-anti-rabbit-IgG (Earthox, 1:5000) at room temperature for 1 hour. Bands were visualized with the ECL kit (Thermo, 34077) and imaged using the GE (AI600). $\beta$-tubulin was used as internal control. Quantitative analysis was performed with ImageJ software. All experiments were repeated for at least three times.

\section{Whole cell electrophysiological recordings}

Acute brain sections were made 3 weeks after retroviral injection, and electrophysiological recordings were performed at $32-34^{\circ} \mathrm{C}$, as previously described (Ge et al., 2006). Briefly, mice were deeply anesthetized with isoflurane, and brain was removed and acute brain slices were prepared. GFP-labeled neurons were identified under fluorescent microscope and whole-cell patchclamp recordings were performed. Miniature excitatory postsynaptic currents (mEPSCs) were recorded in the presence of tetrodotoxin $(1 \mu \mathrm{M})$ and picrotoxin $(100 \mu \mathrm{M})$ at a holding potential of $-70 \mathrm{mV}$. Miniature events were automatically detected and then analyzed using Clampfit software.

\section{Behavior procedures}

\section{1) Contextual fear conditioning (CFC) and test}

Mice were trained in a conditioning chamber $(18 \mathrm{~cm} \times 18 \mathrm{~cm} \times 30 \mathrm{~cm}$; Coulbourn, Whitehall, PA), containing a stainless-steel shock-grid floor (context A). During the training, mice were placed in the 
chamber and received a single foot shock $(0.75 \mathrm{~mA}, 2 \mathrm{~s}$ duration) after $2 \mathrm{~min}$. Mice were taken out of the training chamber 1 min after the foot shock and placed back into their home cages. After training, mice were housed under standard conditions with $12 \mathrm{hr}$ light/dark cycle till test. 24 hours later, mice were placed back in context A for 5 min, without foot shock. Freezing behavior of animals was monitored via overhead cameras and measured by an automated scoring system.

\section{2) Pattern separation trainings and tests}

Mice received CFC training in context A on day 0 . From day 1, mice were exposed to both context A and context B, 4 hours apart with random order, for 12 consecutive days. In context A, mice were exposed to the context for 3 -min followed by a 2 -s foot shock $(0.75 \mathrm{~mA})$ and then 1 -min stay. In context $\mathrm{B}$, mice were allowed to stay for 3 min without foot shock. Context B is a similar context sharing many features with context A, including the same stainless-steel grid floor and roof, but only different with striped pattern in front and back walls. The freezing of mice in two consecutive days with contexts A and B in different orders was averaged as one session to minimize variation.

\section{3) Novel location and novel object recognition tests:}

For novel location recognition test, mice were placed in a normally illuminated box $(45 \mathrm{~cm} \times 45 \mathrm{~cm} \times 35$ $\mathrm{cm}$ ) with an overhead camera, and allowed for habituation for $10 \mathrm{~min}$ and then put back to homecage. One hour later, two identical objects were place close to two corners in the box; mice were put in the box and allowed to freely explore for $10 \mathrm{~min}$. Another hour later, before the test session, one of the two identical objects was place at a different location (novel location), while the other object was not moved; mice were put back in the box for $10 \mathrm{~min}$, and the time of their exploration on the two objects were recorded and analyzed.

For novel object recognition test, mice were placed in a normally illuminated box $(45 \mathrm{~cm} \times 45 \mathrm{~cm} \times 35$ $\mathrm{cm}$ ) with an overhead camera, and allowed for habituation for $10 \mathrm{~min}$ and then put back to homecage. One hour later, two identical objects were place close to two corners in the box; mice were put in the box and 
allowed to freely explore for $10 \mathrm{~min}$. Another hour later, before the test session, one of the two identical objects was replace with a different object (novel object), while the other object was not changed or moved; mice were put back in the box for $10 \mathrm{~min}$, and the time of their exploration on the two objects were recorded and analyzed.

The discrimination index was calculated as: $\left(\right.$ Time $_{\text {novel }}-$ Time $\left._{\text {familiar }}\right) /\left(\right.$ Time $_{\text {novel }}+$ Time $\left._{\text {familiar }}\right)$.

\section{Statistical analysis}

Data were analyzed using GraphPad Prism 8.0 software. Statistical analysis was carried out using twotailed unpaired t-tests or otherwise indicated in the figure legends. For analyzing size of cell clusters, twotailed unpaired t-tests were performed for the average clonal size, following Kolmogorov-Smirnov tests for the cumulative distributions. For the statistical analysis of the discrimination index in the pattern separation tests, two-way RM ANOVA were used to analyze the difference between two groups. Data were presented using box-and-whisker plots or scatter plots. For box-and-whisker plots, whiskers represent the minimum and maximum, the box represent the upper and lower quartiles, the line in the middle represents the median, and the "+" represents the mean. For the scatter plots, data are presented as the mean \pm SEM. Statistical significance was considered when $\mathrm{P}<0.05$.

\section{Acknowledgments}

This work was supported by the National Key R\&D Program of China (2017YFA0104200), the Zhejiang Provincial Natural Science Foundation of China (LR17C090001), the National Natural Science Foundation of China (32071021) and startup funds to Y.G.; and the National Natural Science Foundation of China (32070975), the Zhejiang Provincial Natural Science Foundation of China (R21C090002) to La. W. We are grateful to the Core Facilities of Zhejiang University School of Medicine for technical assistance. 


\section{Author contributions}

Z.H., La.W. and Y.G. designed all the experiments; Z.H. conducted most of the experiments, including most plasmid construction, virus production, viral injection, imaging, electrophysiology, behavioral experiments and related analysis; J.M. did western blots and analysis; H.Y. constructed XFP plasmid vectors and some imaging; X.L. and C.W. did some imaging and analysis; Li.W. provided Ai14 mouse line; B.S. provided Nestin-Cre and Nestin-GFP mouse lines; Z.C. provided Nestin-Cre ${ }^{\text {ERT2 }}$ mouse line; Z.H., J.M., La.W. and Y.G. discussed the results and wrote the manuscript. All authors read and discussed about the manuscript.

Conflict of interest: The authors declare that they have no conflict of interest. 


\section{References}

Anacker, C., and Hen, R. (2017). Adult hippocampal neurogenesis and cognitive flexibility - linking memory and mood. Nature reviews Neuroscience 18(6), 335-346.

Balzer, E., Heine, C., Jiang, Q., Lee, V.M., and Moss, E.G. (2010). LIN28 alters cell fate succession and acts independently of the let-7 microRNA during neurogliogenesis in vitro. Development 137(6), 891-900.

Cai, W.Y., Wei, T.Z., Luo, Q.C., Wu, Q.W., Liu, Q.F., Yang, M., Ye, G.D., Wu, J.F., Chen, Y.Y., Sun, G.B., Liu, Y.J., Zhao, W.X., Zhang, Z.M., and Li, B.A. (2013). The Wnt-beta-catenin pathway represses let-7 microRNA expression through transactivation of Lin28 to augment breast cancer stem cell expansion. Journal of cell science 126(Pt 13), 2877-2889.

Choi, S.H., et al. (2018). Combined adult neurogenesis and BDNF mimic exercise effects on cognition in an Alzheimer's mouse model. Science 361(6406).

Christian, K.M., Song, H., and Ming, G.L. (2014). Functions and dysfunctions of adult hippocampal neurogenesis. Annual review of neuroscience 37(243-262.

Cimadamore, F., Amador-Arjona, A., Chen, C., Huang, C.T., and Terskikh, A.V. (2013). SOX2-LIN28/let-7 pathway regulates proliferation and neurogenesis in neural precursors. Proceedings of the National Academy of Sciences of the United States of America 110(32), E3017-3026.

Dillon, S.E., Tsivos, D., Knight, M., McCann, B., Pennington, C., Shiel, A.I., Conway, M.E., Newson, M.A., Kauppinen, R.A., and Coulthard, E.J. (2017). The impact of ageing reveals distinct roles for human dentate gyrus and CA3 in pattern separation and object recognition memory. Scientific reports 7(1), 14069.

Erben, L., and Buonanno, A. (2019). Detection and Quantification of Multiple RNA Sequences Using Emerging Ultrasensitive Fluorescent In Situ Hybridization Techniques. Current protocols in neuroscience $87(1)$, e63.

Gao, Z., Ure, K., Ables, J.L., Lagace, D.C., Nave, K.A., Goebbels, S., Eisch, A.J., and Hsieh, J. (2009). Neurod1 is essential for the survival and maturation of adult-born neurons. Nature neuroscience 12(9), 1090-1092.

Ge, S., Goh, E.L., Sailor, K.A., Kitabatake, Y., Ming, G.L., and Song, H. (2006). GABA regulates synaptic integration of newly generated neurons in the adult brain. Nature 439(7076), 589-593.

Goncalves, J.T., Schafer, S.T., and Gage, F.H. (2016). Adult Neurogenesis in the Hippocampus: From Stem Cells to Behavior. Cell 167(4), 897-914.

Gu, Y., Arruda-Carvalho, M., Wang, J., Janoschka, S.R., Josselyn, S.A., Frankland, P.W., and Ge, S. (2012). Optical controlling reveals time-dependent roles for adult-born dentate granule cells. Nature 
neuroscience 15(12), 1700-1706.

Hoppler, S., Brown, J.D., and Moon, R.T. (1996). Expression of a dominant-negative Wnt blocks induction of MyoD in Xenopus embryos. Genes \& development 10(21), 2805-2817.

Jang, M.H., Bonaguidi, M.A., Kitabatake, Y., Sun, J., Song, J., Kang, E., Jun, H., Zhong, C., Su, Y., Guo, J.U., Wang, M.X., Sailor, K.A., Kim, J.Y., Gao, Y., Christian, K.M., Ming, G.L., and Song, H. (2013). Secreted frizzled-related protein 3 regulates activity-dependent adult hippocampal neurogenesis. Cell stem cell 12(2), 215-223.

Kirschen, G.W., Shen, J., Tian, M., Schroeder, B., Wang, J., Man, G., Wu, S., and Ge, S. (2017). Active Dentate Granule Cells Encode Experience to Promote the Addition of Adult-Born Hippocampal Neurons. The Journal of neuroscience : the official journal of the Society for Neuroscience 37(18), 4661-4678.

Kuhn, H.G., Dickinson-Anson, H., and Gage, F.H. (1996). Neurogenesis in the dentate gyrus of the adult rat: age-related decrease of neuronal progenitor proliferation. The Journal of neuroscience : the official journal of the Society for Neuroscience 16(6), 2027-2033.

Kumamoto, N., Gu, Y., Wang, J., Janoschka, S., Takemaru, K., Levine, J., and Ge, S. (2012). A role for primary cilia in glutamatergic synaptic integration of adult-born neurons. Nature neuroscience 15(3), 399-405, S391.

Kuwabara, T., Hsieh, J., Muotri, A., Yeo, G., Warashina, M., Lie, D.C., Moore, L., Nakashima, K., Asashima, M., and Gage, F.H. (2009). Wnt-mediated activation of NeuroD1 and retro-elements during adult neurogenesis. Nature neuroscience 12(9), 1097-1105.

Lavado, A., Lagutin, O.V., Chow, L.M., Baker, S.J., and Oliver, G. (2010). Prox1 is required for granule cell maturation and intermediate progenitor maintenance during brain neurogenesis. PLoS biology 8(8).

Lee, S.W., Clemenson, G.D., and Gage, F.H. (2012). New neurons in an aged brain. Behavioural brain research 227(2), 497-507.

Lie, D.C., Colamarino, S.A., Song, H.J., Desire, L., Mira, H., Consiglio, A., Lein, E.S., Jessberger, S., Lansford, H., Dearie, A.R., and Gage, F.H. (2005). Wnt signalling regulates adult hippocampal neurogenesis. Nature 437(7063), 1370-1375.

Meyers, E.A., Gobeske, K.T., Bond, A.M., Jarrett, J.C., Peng, C.Y., and Kessler, J.A. (2016). Increased bone morphogenetic protein signaling contributes to age-related declines in neurogenesis and cognition. Neurobiology of aging 38(164-175.

Ming, G.L., and Song, H. (2011). Adult neurogenesis in the mammalian brain: significant answers and significant questions. Neuron 70(4), 687-702. 
Miranda, C.J., Braun, L., Jiang, Y., Hester, M.E., Zhang, L., Riolo, M., Wang, H., Rao, M., Altura, R.A., and Kaspar, B.K. (2012). Aging brain microenvironment decreases hippocampal neurogenesis through Wntmediated survivin signaling. Aging cell 11(3), 542-552.

Moss, E.G., Lee, R.C., and Ambros, V. (1997). The cold shock domain protein LIN-28 controls developmental timing in C. elegans and is regulated by the lin-4 RNA. Cell 88(5), 637-646.

Nakashiba, T., Cushman, J.D., Pelkey, K.A., Renaudineau, S., Buhl, D.L., McHugh, T.J., Rodriguez Barrera, V., Chittajallu, R., Iwamoto, K.S., McBain, C.J., Fanselow, M.S., and Tonegawa, S. (2012). Young dentate granule cells mediate pattern separation, whereas old granule cells facilitate pattern completion. Cell 149(1), 188-201.

Ngwenya, L.B., Heyworth, N.C., Shwe, Y., Moore, T.L., and Rosene, D.L. (2015). Age-related changes in dentate gyrus cell numbers, neurogenesis, and associations with cognitive impairments in the rhesus monkey. Frontiers in systems neuroscience $9(102$.

Petri, R., Pircs, K., Jonsson, M.E., Akerblom, M., Brattas, P.L., Klussendorf, T., and Jakobsson, J. (2017). let7 regulates radial migration of new-born neurons through positive regulation of autophagy. The EMBO journal 36(10), 1379-1391.

Romer-Seibert, J.S., Hartman, N.W., and Moss, E.G. (2019). The RNA-binding protein LIN28 controls progenitor and neuronal cell fate during postnatal neurogenesis. FASEB journal : official publication of the Federation of American Societies for Experimental Biology 33(3), 3291-3303.

Sahay, A., Scobie, K.N., Hill, A.S., O'Carroll, C.M., Kheirbek, M.A., Burghardt, N.S., Fenton, A.A., Dranovsky, A., and Hen, R. (2011a). Increasing adult hippocampal neurogenesis is sufficient to improve pattern separation. Nature 472(7344), 466-470.

Sahay, A., Wilson, D.A., and Hen, R. (2011b). Pattern separation: a common function for new neurons in hippocampus and olfactory bulb. Neuron 70(4), 582-588.

Schafer, S.T., Han, J., Pena, M., von Bohlen Und Halbach, O., Peters, J., and Gage, F.H. (2015). The Wnt adaptor protein ATP6AP2 regulates multiple stages of adult hippocampal neurogenesis. The Journal of neuroscience : the official journal of the Society for Neuroscience 35(12), 4983-4998.

Seib, D.R., Corsini, N.S., Ellwanger, K., Plaas, C., Mateos, A., Pitzer, C., Niehrs, C., Celikel, T., and MartinVillalba, A. (2013). Loss of Dickkopf-1 restores neurogenesis in old age and counteracts cognitive decline. Cell stem cell 12(2), 204-214.

Shinoda, G., Shyh-Chang, N., Soysa, T.Y., Zhu, H., Seligson, M.T., Shah, S.P., Abo-Sido, N., Yabuuchi, A., Hagan, J.P., Gregory, R.I., Asara, J.M., Cantley, L.C., Moss, E.G., and Daley, G.Q. (2013). Fetal deficiency of lin28 programs life-long aberrations in growth and glucose metabolism. Stem cells 31(8), 
$1563-1573$.

Shyh-Chang, N., and Daley, G.Q. (2013). Lin28: primal regulator of growth and metabolism in stem cells. Cell stem cell 12(4), 395-406.

Song, H., Stevens, C.F., and Gage, F.H. (2002). Astroglia induce neurogenesis from adult neural stem cells. Nature 417(6884), 39-44.

Spalding, K.L., Bergmann, O., Alkass, K., Bernard, S., Salehpour, M., Huttner, H.B., Bostrom, E., Westerlund, I., Vial, C., Buchholz, B.A., Possnert, G., Mash, D.C., Druid, H., and Frisen, J. (2013). Dynamics of hippocampal neurogenesis in adult humans. Cell 153(6), 1219-1227.

Stark, S.M., Yassa, M.A., and Stark, C.E. (2010). Individual differences in spatial pattern separation performance associated with healthy aging in humans. Learning \& memory 17(6), 284-288.

van Praag, H., Schinder, A.F., Christie, B.R., Toni, N., Palmer, T.D., and Gage, F.H. (2002). Functional neurogenesis in the adult hippocampus. Nature 415(6875), 1030-1034.

Viswanathan, S.R., and Daley, G.Q. (2010). Lin28: A microRNA regulator with a macro role. Cell 140(4), 445-449.

Wang, J., Shen, J., Kirschen, G.W., Gu, Y., Jessberger, S., and Ge, S. (2019). Lateral dispersion is required for circuit integration of newly generated dentate granule cells. Nature communications 10(1), 3324.

Yang, M., Yang, S.L., Herrlinger, S., Liang, C., Dzieciatkowska, M., Hansen, K.C., Desai, R., Nagy, A., Niswander, L., Moss, E.G., and Chen, J.F. (2015). Lin28 promotes the proliferative capacity of neural progenitor cells in brain development. Development 142(9), 1616-1627.

Yang, Z., Jun, H., Choi, C.I., Yoo, K.H., Cho, C.H., Hussaini, S.M.Q., Simmons, A.J., Kim, S., van Deursen, J.M., Baker, D.J., and Jang, M.H. (2017). Age-related decline in BubR1 impairs adult hippocampal neurogenesis. Aging cell 16(3), 598-601.

Yao, K., Qiu, S., Tian, L., Snider, W.D., Flannery, J.G., Schaffer, D.V., and Chen, B. (2016). Wnt Regulates Proliferation and Neurogenic Potential of Muller Glial Cells via a Lin28/let-7 miRNA-Dependent Pathway in Adult Mammalian Retinas. Cell reports 17(1), 165-178.

Yousef, H., Morgenthaler, A., Schlesinger, C., Bugaj, L., Conboy, I.M., and Schaffer, D.V. (2015). AgeAssociated Increase in BMP Signaling Inhibits Hippocampal Neurogenesis. Stem cells 33(5), 15771588.

Yu, J., Vodyanik, M.A., Smuga-Otto, K., Antosiewicz-Bourget, J., Frane, J.L., Tian, S., Nie, J., Jonsdottir, G.A., Ruotti, V., Stewart, R., Slukvin, II, and Thomson, J.A. (2007). Induced pluripotent stem cell lines derived from human somatic cells. Science 318(5858), 1917-1920. 


\section{Figure legends}

Figure 1. Expression of Lin28a in the DG of adult brain decreases with age. (A) Representative RNAscope images obtained using brain sections from Nestin-GFP mice, with negative control (Neg-ctrl), positive control (Pos-ctrl), Lin28a and Lin28b probes, respectively. Scale bar: $20 \mu \mathrm{m}$. (B) Upper panel: RNAScope images showing Lin28a mRNA in Nestin ${ }^{+}$NPCs in the DG of adult Nestin-GFP mice. White arrows indicate localization of Lin28a mRNA within cell body of Nestin ${ }^{+}$NPCs. Scale bar: $10 \mu \mathrm{m}$. Lower panel: RNAScope images showing Lin28a mRNA in Prox $1^{+}$DGCs in adult mice. Scale bar: $10 \mu \mathrm{m}$. (C) Upper panel: Zoom-in confocal images showing the presence of Lin28a in Nestin ${ }^{+}$NPCs in the DG of adult Nestin-GFP mice. White arrows indicate colocalization of Lin28a with cell body of Nestin ${ }^{+}$NPCs. Scale bar: $10 \mu \mathrm{m}$. Lower panel: Zoom-in confocal images showing the presence of Lin28a in Prox $1^{+}$DGCs in adult mice. Scale bar: $10 \mu \mathrm{m}$. (D) Representative western blotting showing Lin28a expression level in the DG of young adult $(2 \mathrm{mo})$ and aging $(14 \mathrm{mo})$ mice. $\beta$-tubulin was used as the internal control. (E) Relative expression level of Lin28a in the DG of 2 mo and 14 mo mice. ( 2 mo: N=3 samples, $\mathrm{n}=3$ mice per sample; 14 mo: $\mathrm{N}=4$ samples, $\mathrm{n}=3$ mice per sample; $\mathrm{t}_{5}=6.162$, ** $\left.\mathrm{P}=0.0016\right)$. (F) RNAScope images showing Lin28a mRNA in Nestin ${ }^{+}$NPCs in the DG of 2 mo and 14 mo Nestin-GFP mice. Scale bar: $5 \mu$ m. (G) Number of dots obtained using Lin28a mRNA probes in each Nestin ${ }^{+}$NPC in the DG of 2 mo and 14 mo mice (2 mo: $\mathrm{N}=3$ mice, $\mathrm{n}=82$ cells; 14 mo: $\mathrm{N}=3$ mice, $\mathrm{n}=90$ cells; two-tailed unpaired $\mathrm{t}$-test, $\left.\mathrm{t}_{170}=9.427, * * * * \mathrm{P}<0.0001\right)$. (H) RNAScope images showing Lin28a mRNA in Prox $1^{+}$DGCs in 2 mo and 14 mo mice. Scale bar: $5 \mu \mathrm{m}$. (I) Number of dots obtained using Lin28a mRNA probes in each Prox $1^{+}$DGC in 2 mo and 14 mo mice (2 mo: $\mathrm{N}=3$ mice, $\mathrm{n}=99$ cells; 14 mo: $\mathrm{N}=3$ mice, $\mathrm{n}=111$ cells; two-tailed unpaired $\mathrm{t}$-test, $\mathrm{t}_{208}=12.21$, $* * * * \mathrm{P}<0.0001)$ 
Figure 2. Lin28a is necessary for adult hippocampal neurogenesis and pattern separation. (A) Experimental paradigm for testing pattern separation in mice. (B) The freezing of 2 mo and 10 mo mice in contexts $\mathrm{A}$ and $\mathrm{B}$ in test sessions 1 through 6 . Young mice $(2 \mathrm{mo})$ discriminated the two contexts in session 4, while aging mice (10 mo) showed discrimination in session 6 . (2 mo mice $n=10,10$ mo mice $n=10$; twotailed paired t-test; session 1: $2 \mathrm{mo}_{9}=0.1441, \mathrm{P}=0.8886 ; 10 \mathrm{mo}_{9}=1.609, \mathrm{P}=0.1421$; session $2: 2$ mo $\mathrm{t}_{9}=1.036, \mathrm{P}=0.3272 ; 10 \mathrm{mo}_{9}=0.2128, \mathrm{P}=0.8362 ;$ session $3: 2$ mo $\mathrm{t}_{9}=1.391, \mathrm{P}=0.1976 ; 10 \mathrm{mo} \mathrm{t}_{9}=0.8787$, $\mathrm{P}=0.4024$; session 4: $2 \mathrm{mo}_{9}=2.672, * \mathrm{P}=0.0255 ; 10 \mathrm{mo} \mathrm{t}_{9}=0.6441, \mathrm{P}=0.5356$; session $5: 2$ mo $\mathrm{t}_{9}=6.572$, $* * * \mathrm{P}=0.0001 ; 10 \mathrm{mo}_{9}=2.220, \mathrm{P}=0.0535 ;$ session $6: 2 \mathrm{mo}_{9}=7.818, * * * * \mathrm{P}<0.0001 ; 10$ mo $\mathrm{t}_{9}=3.897$

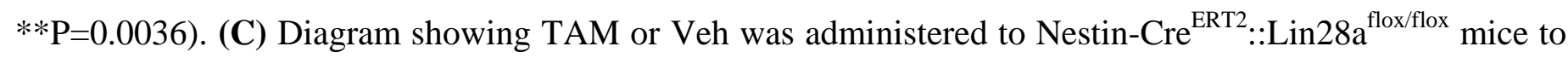
knockout Lin28a from Nestin ${ }^{+}$NPCs. Mice were perfused four weeks later for examination. (D) Confocal images showing $\mathrm{MCM}^{+}$proliferating cells in the SGZ of Nestin-Cre ${ }^{\text {ERT2 }}::$ Lin28a ${ }^{\text {flox/flox }}$ mice treated with Veh or TAM. Scale bar: $50 \mu \mathrm{m}$. (E) Knocking out Lin28a from Nestin ${ }^{+}$NPCs decreased the density of $\mathrm{MCM}^{+}$cells in the SGZ (Veh $\mathrm{n}=5$ mice, TAM $\mathrm{n}=4$ mice; two-tailed unpaired $\mathrm{t}$-test, $\mathrm{t}_{7}=3.638, * * \mathrm{P}=0.0083$ ). (F) Knocking out Lin28a from Nestin ${ }^{+}$NPCs decreased the percentage of MCM2 ${ }^{+}$cells in total cells $\left(\mathrm{DAPI}^{+}\right)$ in the SGZ and GCL (Veh $\mathrm{n}=5$ mice, TAM n=4 mice; two-tailed unpaired t-test, $\left.\mathrm{t}_{7}=3.116, * \mathrm{P}=0.0158\right)$. (G) Confocal images showing $\mathrm{DCX}^{+}$cells in the DG of Nestin-Cre ${ }^{\mathrm{ERT} 2}:$ :Lin $28 \mathrm{a}^{\text {flox/flox }}$ mice treated with Veh or TAM. Scale bar: $50 \mu \mathrm{m}$. (H) Loss of Lin28a from Nestin ${ }^{+}$NPCs decreased the density of DCX ${ }^{+}$cells in the GCL (Veh $\mathrm{n}=5$ mice, TAM $\mathrm{n}=5$ mice; two-tailed unpaired $\mathrm{t}$-test, $\mathrm{t}_{8}=6.252, * * * \mathrm{P}=0.00023$ ). (I) Loss of Lin28a from Nestin ${ }^{+}$NPCs decreased the percentage of $\mathrm{DCX}^{+}$cells in total cells $\left(\mathrm{DAPI}^{+}\right)$in the SGZ and GCL (Veh $\mathrm{n}=5$ mice, TAM $\mathrm{n}=5$ mice; two-tailed unpaired t-test, $\left.\mathrm{t}_{8}=3.656, * * \mathrm{P}=0.0064\right)$. (J) Diagram showing TAM was administered to Nestin-Cre ${ }^{\text {ERT2 }}::$ Lin28a ${ }^{+/+}:: A i 14$ or Nestin-Cre ${ }^{\text {ERT2 }}::$ Lin28a ${ }^{\text {flox/flox }}::$ Ai14 mice. Mice were perfused six weeks later for examination. (K) Confocal images showing dTomato $^{+}$cells in

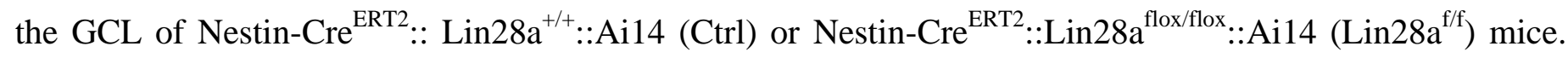
Scale bar: $20 \mu \mathrm{m}$. (L) Loss of Lin28a from Nestin ${ }^{+}$NPCs decreased the density of dTomato ${ }^{+}$cells in the 
GCL (Ctrl n=5 mice, Lin28a $\mathrm{a}^{\mathrm{f} / \mathrm{f}} \mathrm{n}=4$ mice; two-tailed unpaired t-test, $\left.\mathrm{t}_{7}=3.113, * \mathrm{P}=0.0170\right)$. (M) Loss of Lin28a from Nestin ${ }^{+}$NPCs decreased the percentage of dTomato ${ }^{+}$cells in total cells $\left(\mathrm{DAPI}^{+}\right)$in the GCL $\left(\mathrm{Ctrl} n=5\right.$ mice, Lin28 $\mathrm{a}^{\mathrm{f} / \mathrm{f}} \mathrm{n}=4$ mice; two-tailed unpaired $\mathrm{t}$-test, $\left.\mathrm{t}_{7}=4.780, * * \mathrm{P}=0.0020\right)$. (N) Schematics showing that Nestin-Cre ${ }^{\text {ERT2 }}:$ Lin28 ${ }^{\text {flox/flox }}$ mice were treated with Veh $(\mathrm{Ctrl})$ or TAM $\left(\operatorname{Lin} 28 \mathrm{a}^{\mathrm{f} / \mathrm{f}}\right.$ ), followed by behavioral tests six weeks later. (O) The freezing of Veh- and TAM-treated mice in contexts A and B in test sessions 1 through 6 . (Veh mice $\mathrm{n}=12$, TAM mice $\mathrm{n}=10$; two-tailed paired $\mathrm{t}$-test; session 1: Veh $\mathrm{t}_{11}=0.6717, \mathrm{P}=0.5156 ;$ TAM $\mathrm{t}_{9}=1.151, \mathrm{P}=0.2795 ;$ session $2:$ Veh $\mathrm{t}_{11}=0.8907, \mathrm{P}=0.3921 ;$ TAM $\mathrm{t}_{9}=1.177$, $\mathrm{P}=0.2694 ;$ session 3: Veh $\mathrm{t}_{11}=2.867, * \mathrm{P}=0.0153 ;$ TAM $\mathrm{t}_{9}=0.6078, \mathrm{P}=0.5583 ;$ session $4:$ Veh $\mathrm{t}_{11}=3.427, * * \mathrm{P}=$ 0.0057; $\mathrm{TAM}_{9}=1.925, \mathrm{P}=0.0863 ;$ session 5: Veh $\mathrm{t}_{11}=5.504, * * * \mathrm{P}=0.0002 ;$ TAM $\mathrm{t}_{9}=3.434, * * \mathrm{P}=0.0075$ session 6: Veh $\left.\mathrm{t}_{11}=3.530, * * \mathrm{P}=0.0047 ; \mathrm{TAM} \mathrm{t}_{9}=2.614, * \mathrm{P}=0.0281\right)$.

Figure 3. Overexpression of Lin28a increases the progenies of individual NPCs. (A) Schematics showing that FLEX retroviral vectors expressing GFP (Ctrl) or GFP-p2A-Lin28a (Lin28a-OE) were injected into the DG of Nestin-Cre mice. (B) A confocal image showing the sparse labeling of an individual cluster of newborn cells in the DG. Scale bar: $50 \mu \mathrm{m}$. Inset shows an enlarged image of the 2-cell cluster in the square area marked by dotted line. Scale bar: $10 \mu \mathrm{m}$. (C) Confocal images showing examples of cell clusters labeled by Ctrl or Lin28a-OE retroviruses in the DG of Nestin-Cre mice. Scale bar: $10 \mu \mathrm{m}$. (D) Cumulative distribution of the size of cell clusters labeled by $\mathrm{Ctrl}$ or Lin28a-OE retroviruses. $(\mathrm{Ctrl} \mathrm{N}=11$ mice, $\mathrm{n}=61$ cell clusters; Lin28a-OE N=8 mice, $\mathrm{n}=40$ cell clusters; Kolmogorov-Smirnov test, $* * * * \mathrm{P}<0.0001)$. (E) The average size of cell clusters labeled by $\mathrm{Ctrl}$ or Lin28a-OE retroviruses. ( $\mathrm{Ctrl} \mathrm{N}=11$ mice, $\mathrm{n}=61$ cell clusters; Lin28a-OE $\mathrm{N}=8$ mice, $\mathrm{n}=40$ cell clusters; two-tailed unpaired $\mathrm{t}$-test, $\left.\mathrm{t}_{99}=5.700, * * * * \mathrm{P}<0.0001\right) . \quad(\mathbf{F})$ Schematics showing combination of Cre-dependent m/n/cXFP retroviral vectors used for clonal labeling in Nestin-Cre mice in Ctrl or Lin28a-OE groups. (G) Confocal images showing labeling of cell clusters in the DG of Nestin-Cre mice by Ctrl or Lin28a-OE combination of $\mathrm{m} / \mathrm{n} / \mathrm{cXFP}$ retroviral vectors. Different numbers 
indicate different cell clusters. In Lin28a-OE group, only $\mathrm{GFP}^{+}$cell clusters were selected for analysis. Scale bar: $10 \mu \mathrm{m}$. (H) Cumulative distribution of the size of cell clusters labeled in Ctrl or Lin28a-OE groups. (Ctrl $\mathrm{N}=8$ mice, $\mathrm{n}=77$ cell clusters; Lin28a-OE $\mathrm{N}=7$ mice, $\mathrm{n}=52$ cell clusters; Kolmogorov-Smirnov test, $* * * * \mathrm{P}<0.0001)$. (I) The average size of cell clusters labeled by Ctrl or Lin28a-OE combination of $\mathrm{m} / \mathrm{n} / \mathrm{cXFP}$ retroviral vectors. ( $\mathrm{Ctrl} \mathrm{N}=8$ mice, $\mathrm{n}=77$ cell clusters; Lin28a-OE $\mathrm{N}=7$ mice, $\mathrm{n}=52$ cell clusters; two-tailed unpaired t-test, $\left.\mathrm{t}_{127}=7.123, * * * * \mathrm{P}<0.0001\right)$.

Figure 4. The effect of Lin28a overexpression on cell cycle, survival and differentiation. (A) Experimental scheme showing the analysis of cell cycles of hippocampal NPCs in vivo. (B) Confocal images showing GFP-labeled newborn cells in the DG using Ctrl or Lin28a-OE retroviruses, co-labeled with BrdU and/or MCM2. Scale bar: $5 \mu \mathrm{m}$. (C) Percentage of $\mathrm{GFP}^{+} \mathrm{BrdU}^{+}$cells (two-tailed unpaired t-test, $\mathrm{t}_{16}=2.7507$, $* \mathrm{P}=0.0142$ ) and $\mathrm{GFP}^{+} \mathrm{BrdU}^{+} \mathrm{MCM}^{+}$cells (two-tailed unpaired t-test, $\mathrm{t}_{16}=3.5555, * * \mathrm{P}=0.0040$ ) in $\mathrm{GFP}$ labeled cells (Ctrl N=10 mice, $n=290$ cells; Lin28a-OE N=8 mice, $n=253$ cells). (D) Images showing aCas- $3^{+}$ GFP-expressing newborn cells labeled by Ctrl and Lin28a-OE retroviruses in the DG. White arrows indicate an aCas- $3^{+}$GFP-labeled cell. Scale bar: $10 \mu \mathrm{m}$. (E) Percentage of aCas- $3^{+}$cells in GFP-labeled newborn cells in the DG. (Ctrl N=4 mice, $n=794$ cells; Lin28a-OE $N=4$ mice, $n=339$ cells; two-tailed unpaired t-test, $\mathrm{t}_{6}=0.1449, \mathrm{P}=0.8896$ ). (F) Images showing $\mathrm{DCX}^{+}$GFP-expressing newborn cells labeled by Ctrl or Lin28aOE retroviruses in the DG. White arrows indicate $\mathrm{GFP}^{+} \mathrm{DCX}^{+}$cells. Scale bar: $10 \mu \mathrm{m}$. (G) Images showing a $\mathrm{GFP}^{+} \mathrm{s} 100 \beta^{+}$astrocytes labeled by $\mathrm{Ctrl}$ or Lin28a-OE retroviruses in the DG, indicated by white arrows. Scale bar: $10 \mu \mathrm{m}$. (H) Images showing $\mathrm{GFP}^{+} \mathrm{GFAP}^{+} \mathrm{s} 100 \beta^{-}$radial glia-like NPCs labeled by Ctrl or Lin28a-OE

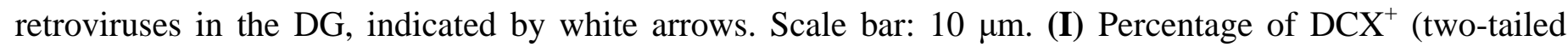
unpaired t-test, $\left.\mathrm{t}_{16}=1.2006, \mathrm{P}=0.2474\right), \mathrm{GFAP}^{+} \mathrm{s}_{100 \beta^{-}}$(two-tailed unpaired $\mathrm{t}$-test, $\left.\mathrm{t}_{16}=0.1215, \mathrm{P}=0.9048\right)$ and $\mathrm{s} 100 \beta^{+}$(two-tailed unpaired $\mathrm{t}$-test, $\left.\mathrm{t}_{16}=2.1156, \mathrm{P}=0.0504\right)$ cells in GFP-labeled newborn cells $(\mathrm{Ctrl} \mathrm{N}=10$ mice; Lin28a-OE N=8 mice), seven days after viral injection. 


\section{Figure 5. Lin28a regulates the development and functional integration of newborn neurons in the adult}

DG. (A) Representative images of newborn neurons in the DG of adult mice labeled by retrovirus expressing GFP (Ctrl) or GFP-p2A-Lin28a (Lin28a-OE) at 1, 2, 3, and 4 wpi. Images were converted into black and white. Scale bar: $20 \mu \mathrm{m}$. (B) Sholl analysis of dendrites of Ctrl or Lin28a-OE newborn neurons at 1, 2, 3, and 4 wpi. (C) Lin28a-OE neurons showed longer total dendritic length than Ctrl neurons at 1, 2, 3, and 4 wpi. (1 wpi: Ctrl $\mathrm{N}=4$ mice, $\mathrm{n}=60$ cells; Lin28a-OE $\mathrm{N}=4$ mice, $\mathrm{n}=52$ cells; two-tailed unpaired $\mathrm{t}$-test, $\mathrm{t}_{110}=4.742$, ****P<0.0001; 2 wpi: Ctrl N=3 mice, $\mathrm{n}=27$ cells; Lin28a-OE $\mathrm{N}=3$ mice, $\mathrm{n}=44$ cells; two-tailed unpaired $\mathrm{t}-$ test, $\mathrm{t}_{69}=9.921, * * * * \mathrm{P}<0.0001 ; 3$ wpi: $\mathrm{Ctrl} \mathrm{N}=3$ mice, $\mathrm{n}=34$ cells; Lin28a-OE N=3 mice, $\mathrm{n}=23$ cells; twotailed unpaired t-test, $\mathrm{t}_{55}=8.371, * * * * \mathrm{P}<0.0001 ; 4$ wpi: $\mathrm{Ctrl} \mathrm{N}=3$ mice, $\mathrm{n}=47$ cells; Lin28a-OE $\mathrm{N}=3$ mice, $\mathrm{n}=23$ cells; two-tailed unpaired $\mathrm{t}$-test, $\mathrm{t}_{68}=7.6342$, $* * * * \mathrm{P}<0.0001$ ). (D) Lin28a-OE neurons showed more dendritic branches than $\mathrm{Ctrl}$ neurons at 1, 2, 3, and 4 wpi. ( 1 wpi: $\mathrm{Ctrl} \mathrm{N}=4$ mice, $\mathrm{n}=60$ cells; Lin28a-OE N=4 mice, $\mathrm{n}=52$ cells; two-tailed unpaired $\mathrm{t}$-test, $\mathrm{t}_{110}=5.263$, $* * * * \mathrm{P}<0.0001 ; 2$ wpi: $\mathrm{Ctrl} \mathrm{N}=3$ mice, $\mathrm{n}=27$ cells; Lin28a-OE $\mathrm{N}=3$ mice, $\mathrm{n}=44$ cells; two-tailed unpaired $\mathrm{t}$-test, $\mathrm{t}_{69}=2.319, * \mathrm{P}=0.0233 ; 3$ wpi: Ctrl $\mathrm{N}=3$ mice, $\mathrm{n}=34$ cells; Lin28a-OE $\mathrm{N}=3$ mice, $\mathrm{n}=23$ cells; two-tailed unpaired $\mathrm{t}$-test, $\mathrm{t}_{55}=4.977, * * * * \mathrm{P}<0.0001 ; 4$ wpi: Ctrl $\mathrm{N}=3$ mice, $\mathrm{n}=47$ cells; Lin28a-OE $\mathrm{N}=3$ mice, $\mathrm{n}=23$ cells; two-tailed unpaired $\mathrm{t}$-test, $\mathrm{t}_{68}=6.619$, $* * * * \mathrm{P}<0.0001)$. (E) Images of newborn neurons in Lin28 $\mathrm{a}^{\text {flox/flox }}$ mice labeled by retrovirus expressing GFP (Ctrl) or GFP-p2A-Cre $\left(\operatorname{Lin} 28 \mathrm{a}^{\mathrm{f} / \mathrm{f}}\right)$ at 3 wpi. Scale bar: $20 \mu \mathrm{m}$. (F) Sholl analysis of dendrites of Ctrl or Lin $28 \mathrm{a}^{\mathrm{f} / \mathrm{f}}$ newborn neurons at 3 wpi. (G) Lin $28 \mathrm{a}^{\mathrm{f} / \mathrm{f}}$ neurons showed shorter total dendritic length than Ctrl neurons at 3 wpi. (Ctrl N=3 mice, $n=26$ cells; Lin28 ${ }^{\mathrm{f} / \mathrm{f}} \mathrm{N}=4$ mice, $\mathrm{n}=53$ cells; two-tailed unpaired t-test, $\left.\mathrm{t}_{77}=5.179, * * * * \mathrm{P}<0.0001\right)$. $(\mathbf{H})$ Lin $28 \mathrm{a}^{\mathrm{f} / \mathrm{f}}$ neurons showed fewer dendritic branches than Ctrl neurons at 3 wpi. (Ctrl N=3 mice, $\mathrm{n}=26$ cells; Lin28 $\mathrm{a}^{\mathrm{f} / \mathrm{f}} \mathrm{N}=4$ mice, $\mathrm{n}=53$ cells; two-tailed unpaired $\mathrm{t}$-test, $\mathrm{t}_{77}=6.830$, $* * * * \mathrm{P}<0.0001)$. (I) Confocal images showing dendritic spines of Ctrl or Lin28a-OE newborn neurons in C57 mice (upper panel), and Ctrl or Lin28 $\mathrm{a}^{\mathrm{f} / \mathrm{f}}$ newborn neurons in Lin28 $\mathrm{a}^{\text {flox/flox }}$ mice (lower panel) at 3 wpi. Scale 
bar: $2 \mu \mathrm{m}$. (J) Spine density in newborn neurons at 3 wpi. (C57 mice: Ctrl N=3 mice, $\mathrm{n}=30$ dendritic segments; Lin28-OE N=3 mice, $\mathrm{n}=30$ dendritic segments; two-tailed unpaired $\mathrm{t}$-test, $\mathrm{t}_{58}=5.429, \mathrm{P}<0.0001$; Lin28 $\mathrm{a}^{\text {flox/flox }}$ mice: Ctrl $\mathrm{N}=3$ mice, $\mathrm{n}=22$ dendritic segments; Lin28 ${ }^{\mathrm{f} / \mathrm{f}} \mathrm{N}=3$ mice, $\mathrm{n}=18$ dendritic segments; two-tailed unpaired t-test, $\left.\mathrm{t}_{38}=6.248, * * * * \mathrm{P}<0.0001\right)$. (K) Representative traces of mEPSCs recorded from Ctrl and Lin28a-OE newborn neurons at 3 wpi. (L) Cumulative distribution of inter-event intervals of mEPSCs in Ctrl and Lin28a-OE neurons. (M) Cumulative distribution of amplitude of mEPSCs in Ctrl and Lin28a-OE neurons. (N) Representative traces of mEPSCs recorded from Ctrl and Lin28a ${ }^{\mathrm{f} / \mathrm{f}}$ neurons at 3 wpi. (O) Cumulative distribution of inter-event intervals of mEPSCs in Ctrl and Lin $28 \mathrm{a}^{\mathrm{f} / \mathrm{f}}$ neurons. (P) Cumulative distribution of amplitude of mEPSCs in Ctrl and Lin28a ${ }^{\mathrm{f} / \mathrm{f}}$ neurons. (Q) mEPSCs frequency increased in Lin28a-OE neurons but decreased in Lin28 $\mathrm{a}^{\mathrm{f} / \mathrm{f}}$ neurons. (C57 mice: Ctrl N=3 mice, $\mathrm{n}=12$ neurons; Lin28-OE $\mathrm{N}=3$ mice, $\mathrm{n}=12$ neurons; two-tailed unpaired t-test, $\mathrm{t}_{22}=4.301, * * * \mathrm{P}=0.0003 ;$ Lin $28 \mathrm{a}^{\text {flox/flox }}$ mice: Ctrl $\mathrm{N}=3$ mice, $\mathrm{n}=9$ neurons; $\operatorname{Lin} 28 \mathrm{a}^{\mathrm{f} / \mathrm{f}} \mathrm{N}=3$ mice, $\mathrm{n}=10$ neurons; two-tailed unpaired t-test, $\left.\mathrm{t}_{17}=3.509, * * \mathrm{P}=0.0027\right)$. $(\mathbf{R})$ mEPSCs amplitude did not significantly change in Lin28a-OE or Lin28a ${ }^{\mathrm{f} / \mathrm{f}}$ neurons. (C57 mice: Ctrl N=3 mice, $\mathrm{n}=12$ neurons; Lin28-OE $\mathrm{N}=3$ mice, $\mathrm{n}=12$ neurons; two-tailed unpaired t-test, $\mathrm{t}_{22}=0.2229, \mathrm{P}=0.8257$; Lin28 $\mathrm{a}^{\text {flox/flox }}$ mice: $\mathrm{Ctrl} \mathrm{N}=3$ mice, $\mathrm{n}=9$ neurons; $\operatorname{Lin} 28^{\mathrm{f} / \mathrm{f}} \mathrm{N}=3$ mice, $\mathrm{n}=10$ neurons; two-tailed unpaired t-test, $\left.\mathrm{t}_{17}=1.042, \mathrm{P}=0.3119\right)$.

Figure 6. Lin28a expression in NPCs is regulated by Wnt- $\beta$-catenin signaling. (A) Schematics showing lentiviral vectors expressing GFP or Wnt3a. (B) Schematics showing that lentiviral vectors were injected into the DG of adult C57 mice. Mice were perfused for examination one week later. (C) Confocal image showing infection of cells in the DG by lentivirus expressing Wnt3a-p2A-GFP. Scale bar: $50 \mu \mathrm{m}$. (D) Representative western blotting showing $\beta$-catenin expression level in the DG of animals injected with lentiviruses expressing GFP or Wnt3a. $\beta$-tubulin was used as internal control. (E) Relative expression level of $\beta$-catenin in the DG of animals injected with GFP or Wnt3a lentiviruses (GFP: $n=8$ mice per sample; Wnt3a: $n=9$ mice 
per sample; $\mathrm{t}_{15}=2.7375, * \mathrm{P}=0.0153$ ). (F) RNAScope images showing colocalization of Lin28a mRNA with cell bodies of Sox2-expressing NPCs (indicated by Sox 2 mRNA) in animals injected with GFP or Wnt3a lentiviruses. Dotted lines outline the cell bodies of interested cells. Insets in the merged images show the localization of Lin28a and Sox 2 mRNA around the nucleus (DAPI) within the cell bodies. Scale bar: $5 \mu \mathrm{m}$. (G) Wnt3a increased the mRNA expression level of Lin28a in Sox2-expressing NPCs. (GFP: N=3 mice, n= 56 cells; Wnt3a: $\mathrm{N}=3$ mice, $\mathrm{n}=62$ cells; two-tailed unpaired $\mathrm{t}$-test, $\left.\mathrm{t}_{116}=3.9875, * * * \mathrm{P}=0.0001\right)$. (H) Upper panel: Schematics showing FLEX lentiviral vectors expressing GFP (Ctrl) or GFP-p2A-Ctnnb1 (Ctnnb1). Lower panel: Schematics showing that FLEX lentiviral vectors expressing GFP or GFP-p2A-Ctnnb1 were injected into the DG of adult Nestin-Cre mice. Mice were perfused for examination one week later. (I) RNAScope images showing colocalization of Lin28a mRNA with cell bodies of GFP-labeled NPCs in the DG of Nestin-Cre mice injected with Cre-dependent lentiviral vectors expressing GFP or Ctnnb1. Scale bar: $5 \mu \mathrm{m}$. (J) Upregulation of Ctnnb1 increased the mRNA expression level of Lin28a in NPCs. (GFP: N=3 mice, $\mathrm{n}=63$ cells; Ctnnb1: $\mathrm{N}=3$ mice, $\mathrm{n}=37$ cells; two-tailed unpaired $\mathrm{t}$-test, $\left.\mathrm{t}_{98}=13.57, * * * * \mathrm{P}<0.0001\right)$.

Figure 7. Lin28a is involved in Wnt-mediated regulation of hippocampal neurogenesis. (A) Schematics showing that adult Nestin-Cre ${ }^{\mathrm{ERT} 2}:: \mathrm{Lin} 28 \mathrm{a}^{\text {flox/flox }}$ mice $\left(\mathrm{Lin} 28 \mathrm{a}^{\mathrm{f} / \mathrm{f}}\right)$ or $\mathrm{Cre}^{-/-}$litter mates $(\mathrm{Ctrl})$ were treated with TAM, followed by injection of lentiviral vectors expressing GFP or Wnt3a in the DG, one week later. Four weeks after viral injection, the animals were perfused. (B) Confocal images showing $\mathrm{DCX}^{+}$newborn neurons in the DG of Ctrl and Lin28 ${ }^{\mathrm{f} / \mathrm{f}}$ mice treated with TAM, and injected with GFP or Wnt3a lentiviruses. Scale bar: $20 \mu \mathrm{m}$. (C) Wnt3a increased the density of DCX ${ }^{+}$cell in the DG of Ctrl mice, but not in Lin $28 \mathrm{a}^{\mathrm{f} / \mathrm{f}}$ mice. $\left(\right.$ Ctrl: GFP $\mathrm{n}=4$ mice, Wnt3a $\mathrm{n}=5$ mice; two-tailed unpaired t-test, $\mathrm{t}_{7}=2.554,{ }^{*} \mathrm{P}=0.0379 ; \operatorname{Lin}_{28 \mathrm{a}}{ }^{\mathrm{f}}: \mathrm{fFP}$ $\mathrm{n}=6$ mice, Wnt3a $\mathrm{n}=6$ mice; two-tailed unpaired t-test, $\mathrm{t} 10=0.3891, \mathrm{P}=0.7054 ; \mathrm{Ctrl}$ GFP vs. Lin28a ${ }^{\mathrm{f} / \mathrm{f}} \mathrm{GFP}$ : two-tailed unpaired t-test, $\mathrm{t}_{8}=6.341, * * * \mathrm{P}=0.0002$ ). (D) Wnt3a increased the percentage of $\mathrm{DCX}^{+}$cell in the total cells $\left(\mathrm{DAPI}^{+}\right)$of the GCL in Ctrl mice, but not in Lin28a ${ }^{\mathrm{f} / \mathrm{f}}$ mice. $(\mathrm{Ctrl}$ : GFP $\mathrm{n}=4$ mice, Wnt3a n=5 mice; 
two-tailed unpaired t-test, $\mathrm{t}_{8}=2.718, * \mathrm{P}=0.0299 ;$ Lin28 $^{\mathrm{f} / \mathrm{f}}$ : GFP $\mathrm{n}=6$ mice, Wnt3a $\mathrm{n}=6$ mice; two-tailed unpaired t-test, $\mathrm{t}_{10}=1.113, \mathrm{P}=0.2918 ;$ Ctrl GFP vs. Lin28 $\mathrm{a}^{\mathrm{f} / \mathrm{f}}$ GFP: two-tailed unpaired t-test, $\mathrm{t}_{8}=3.877$, $* * \mathrm{P}=0.0047)$. (E) Schematics showing that adult Nestin-Cre ${ }^{\mathrm{ERT} 2}:: \mathrm{Lin} 28 \mathrm{a}^{\text {flox/flox }}::$ Ai14 mice $\left(\operatorname{Lin} 28 \mathrm{a}^{\mathrm{f} / \mathrm{f}}\right)$ or Nestin-Cre ${ }^{\text {ERT2}:: A i 14 ~ m i c e ~(C t r l) ~ w e r e ~ t r e a t e d ~ w i t h ~ T A M, ~ f o l l o w e d ~ b y ~ i n j e c t i o n ~ o f ~ l e n t i v i r a l ~ v e c t o r s ~}$ expressing GFP or Wnt3a in the DG, one week later. Four weeks after viral injection, the animals were perfused for further analysis. (F) Confocal images showing dTomato ${ }^{+}$adult-born neurons in the DG of Ctrl and Lin28a $\mathrm{a}^{\mathrm{f} / \mathrm{f}}$ mice treated with TAM, and injected with GFP or Wnt3a lentiviruses. Scale bar: $20 \mu \mathrm{m}$. (G) Wnt3a increased the density of dTomato $^{+}$cell in the DG of Ctrl mice, but not in Lin28a ${ }^{\mathrm{f} / \mathrm{f}}$ mice. (Ctrl: GFP $\mathrm{n}=5$ mice, Wnt3a $\mathrm{n}=5$ mice; two-tailed unpaired t-test, $\mathrm{t}_{8}=2.921, * \mathrm{P}=0.0193 ; \operatorname{Lin} 28 \mathrm{a}^{\mathrm{f} / \mathrm{f}}:$ GFP $\mathrm{n}=6 \mathrm{mice}, \mathrm{Wnt} 3 \mathrm{a}$ $\mathrm{n}=6$ mice; two-tailed unpaired t-test, $\mathrm{t}_{10}=0.03851, \mathrm{P}=0.9700 ; \mathrm{Ctrl}$ GFP vs. Lin $28 \mathrm{a}^{\mathrm{f} / \mathrm{f}} \mathrm{GFP}$ : two-tailed unpaired t-test, $\left.\mathrm{t}_{9}=2.705, * \mathrm{P}=0.0242\right) .(\mathbf{H}) \mathrm{Wnt} 3 \mathrm{a}$ increased the percentage of dTomato ${ }^{+}$cell in the total cells $\left(\mathrm{DAPI}^{+}\right)$ of the GCL in Ctrl mice, but not in Lin28 ${ }^{\mathrm{f} / \mathrm{f}}$ mice. (Ctrl: GFP $\mathrm{n}=5$ mice, Wnt3a $\mathrm{n}=5$ mice; two-tailed unpaired t-test, $\mathrm{t}_{8}=3.531, * * \mathrm{P}=0.0077 ; \operatorname{Lin} 28 \mathrm{a}^{\mathrm{f} / \mathrm{f}}:$ GFP $\mathrm{n}=6$ mice, Wnt3a $\mathrm{n}=6$ mice; two-tailed unpaired t-test, $\mathrm{t}_{10}=0.5937, \mathrm{P}=0.5659 ;$ Ctrl GFP vs. $\operatorname{Lin} 28 \mathrm{a}^{\mathrm{f} / \mathrm{f}}$ GFP: two-tailed unpaired $\mathrm{t}$-test, $\left.\mathrm{t}_{9}=2.714, * \mathrm{P}=0.0238\right)$. (I) Schematics showing lentiviral vectors expressing dTomato or dnWnt1 (upper panel), and FLEX lentiviral vectors expressing GFP (Ctrl) or GFP-p2A-Lin28a (Lin28a-OE) (lower panel). (J) Schematics showing that lentiviral vectors expressing dTomato or dnWnt1 were injected into the DG of adult Nestin-Cre mice, and Cre-dependent Ctrl or Lin28a-OE lentiviral vectors were injected 2 weeks later. Four more weeks later, the animals were perfused. (K) Confocal images showing $\mathrm{DCX}^{+}$newborn neurons in the DG of Ctrl and Lin28 $\mathrm{a}^{\mathrm{f} / \mathrm{f}}$ mice treated with TAM, and injected with GFP or Wnt3a lentiviruses. Scale bar: $20 \mu \mathrm{m} .(\mathbf{L}) \mathrm{dnWnt} 1$ decreased the percentage of $\mathrm{DCX}^{+}$cell in the total cells $\left(\mathrm{DAPI}^{+}\right)$of the GCL, whereas upregulating Lin28a in NPCs recovered the number of $\mathrm{DCX}^{+}$cells. (dTomato: Ctrl $\mathrm{n}=4$ mice, Lin28a-OE $\mathrm{n}=5$ mice; two-tailed unpaired t-test, $\mathrm{t}_{7}=3.993, * * \mathrm{P}=0.0052 ; \mathrm{dnWnt} 1: \mathrm{Ctrl} \mathrm{n}=4$ mice, Lin28a-OE $\mathrm{n}=4$ mice; two-tailed unpaired $\mathrm{t}$ - 
test, $\mathrm{t}_{6}=6.199, * * * \mathrm{P}=0.0008$; dTomato Ctrl vs. dnWnt1 Ctrl: two-tailed unpaired t-test, $\mathrm{t}_{6}=4.421, * * \mathrm{P}=0.0045$ dTomato Lin28a-OE vs. dnWnt1 Lin28a-OE: two-tailed unpaired t-test, $\left.\mathrm{t}_{7}=4.181, * * \mathrm{P}=0.0041\right)$.

Figure 8. Overexpression of Lin28a in NPCs restores neurogenesis in the aging hippocampus and enhances pattern separation. (A) Diagram showing FLEX GFP (Ctrl) or GFP-p2A-Lin28a (Lin28a-OE) lentiviral vectors. (B) The lentiviruses were injected into the DG of young adult Nestin-Cre mice (2 mo), followed by behavioral tests 6 weeks later. (C) Confocal images showing DCX ${ }^{+}$cells in the DG of NestinCre mice injected with FLEX lentivirus expressing GFP (Ctrl) or GFP-p2A-Lin28a (Lin28a-OE). Scale bar: $20 \mu \mathrm{m}$. (D) Density of DCX ${ }^{+}$cells in the DG of Ctrl and Lin28a-OE mice. (Ctrl n=7 mice, Lin28a-OE n=6 mice; two-tailed unpaired t-test, $\left.\mathrm{t}_{11}=4.807, * * * \mathrm{P}=0.0005\right)$. (E) The freezing of Ctrl and Lin28a-OE mice in contexts $A$ and $B$ in test sessions 1 through 6 . (Ctrl mice $n=13$, Lin28a-OE mice $n=13$; two-tailed paired $t-$

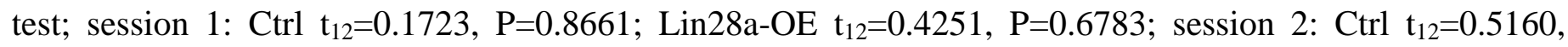
$\mathrm{P}=0.6152 ;$ Lin28a-OE $\mathrm{t}_{12}=2.922, * \mathrm{P}=0.0128$; session 3: $\mathrm{Ctrl}_{12}=2.033, \mathrm{P}=0.0648 ;$ Lin28a-OE $\mathrm{t}_{12}=3.121$, $* * \mathrm{P}=0.0088 ;$ session 4: $\mathrm{Ctrl} \mathrm{t}_{12}=3.662, * * \mathrm{P}=0.0033 ;$ Lin28a-OE $\mathrm{t}_{12}=2.470, * \mathrm{P}=0.0295 ;$ session 5 : Ctrl $\mathrm{t}_{12}=3.925, * * \mathrm{P}=0.0020 ;$ Lin28a-OE $\mathrm{t}_{12}=8.950$, ****P<0.0001; session 6: Ctrl $\mathrm{t}_{12}=5.391$, *** $\mathrm{P}=0.0002$; Lin28a-OE $\left.\mathrm{t}_{12}=6.209, * * * * \mathrm{P}<0.0001\right)$. (F) Diagram showing Cre-dependent Ctrl or Lin28a-OE lentiviruses were injected into the DG of aging Nestin-Cre mice $(12 \mathrm{mo})$, followed by behavioral tests six weeks later. (G) Confocal images showing $\mathrm{DCX}^{+}$cells in the DG of aging Nestin-Cre mice (12 mo) 6 weeks after the injection of FLEX lentivirus expressing GFP (Ctrl) or GFP-p2A-Lin28a (Lin28a-OE). Scale bar: $20 \mu \mathrm{m}$. (H) Density of $\mathrm{DCX}^{+}$cells in the DG of Ctrl and Lin28a-OE mice. (Ctrl n=5 mice, Lin28a-OE n=7 mice; twotailed unpaired t-test, $\left.\mathrm{t}_{10}=3.970, * * \mathrm{P}=0.0026\right)$. (I) The freezing of $\mathrm{Ctrl}$ and Lin28a-OE mice in contexts A and B in test sessions 1 through 6. (Ctrl mice $\mathrm{n}=10$, Lin28a-OE mice $\mathrm{n}=10$; two-tailed paired t-test; session 1: Ctrl $\mathrm{t}_{9}=1.052, \mathrm{P}=0.3203 ; \mathrm{Lin} 28 \mathrm{a}-\mathrm{OE} \mathrm{t}_{9}=0.3730, \mathrm{P}=0.7178 ;$ session $2: \mathrm{Ctrl} \mathrm{t}_{9}=0.4910, \mathrm{P}=0.6352 ; \mathrm{Lin} 28 \mathrm{a}-\mathrm{OE}$ $\mathrm{t}_{9}=2.131, \mathrm{P}=0.0620 ;$ session 3: $\mathrm{Ctrl} \mathrm{t}_{9}=1.606, \mathrm{P}=0.1426 ;$ Lin28a-OE $\mathrm{t}_{9}=1.979, \mathrm{P}=0.0792 ;$ session 4: $\mathrm{Ctrl}$ 
$\mathrm{t}_{9}=1.335, \mathrm{P}=0.2146 ;$ Lin28a-OE $\mathrm{t}_{9}=2.716, * \mathrm{P}=0.0237 ;$ session 5: Ctrl $\mathrm{t}_{9}=1.292, \mathrm{P}=0.2287$ Lin28a-OE $\mathrm{t}_{9}=3.840, * * \mathrm{P}=0.0040 ;$ session $\left.6: \mathrm{Ctrl} \mathrm{t}_{9}=3.214, * \mathrm{P}=0.0106 ; \mathrm{Lin} 28 \mathrm{a}-\mathrm{OE} \mathrm{t}_{9}=8.339, * * * * \mathrm{P}<0.0001\right)$ 


\section{Expanded View Figure legends}

Figure EV1. Expression of Lin28a in the dentate gyrus. (A) Confocal image showing Lin28a protein exists in the DG of adult Nestin-GFP mice. Scale bar: $100 \mu \mathrm{m}$. (B) Confocal images showing Lin28a protein exists in the cells locate in the GCL and SGZ of wildtype (WT) mice, but is absent from the GCL and SGZ of Nestin-Cre::Lin28 $\mathrm{a}^{\text {flox/flox }}\left(\operatorname{Lin} 28 \mathrm{a}^{\mathrm{f} / \mathrm{f}}\right)$ mice. Scale bar: $10 \mu \mathrm{m}$.

\section{Figure EV2. Aging resulted in decreased hippocampal neurogenesis, and the effects on animals'}

behaviors. (A) Experimental paradigm for novel location recognition test. (B) The performance of 2 mo and 10 mo mice in the novel location recognition test. ( 2 mo n=10 mice, two-tailed paired $\mathrm{t}$-test, $\mathrm{t}_{9}=4.458$, $* * \mathrm{P}=0.0016 ; 10$ mo $\mathrm{n}=10$ mice, two-tailed paired $\mathrm{t}$-test, $\left.\mathrm{t}_{9}=0.9220, \mathrm{P}=0.3806\right) .(\mathbf{C}) 10$ mo mice showed impaired discrimination between novel and familiar locations. ( 2 mo n=10 mice, 10 mo n=10 mice, twotailed unpaired t-test, $\mathrm{t}_{18}=3.193, * * \mathrm{P}=0.0050$ ). (D) Experimental paradigm for novel object recognition test. (E) 10 mo mice did not show impaired novel object recognition. (2 mo n=10 mice, two-tailed paired t-test, $\mathrm{t}_{9}=6.184, * * * \mathrm{P}=0.0002 ; 10 \mathrm{mo} \mathrm{n}=10$ mice, two-tailed paired $\mathrm{t}$-test, $\left.\mathrm{t}_{9}=4.439, * * \mathrm{P}=0.0016\right) .(\mathbf{F}) 2$ mo and 10 mo mice showed similar discrimination in novel object test. ( 2 mo $\mathrm{n}=10$ mice, $10 \mathrm{mo} \mathrm{n}=10 \mathrm{mice}$, two-tailed unpaired t-test, $\left.\mathrm{t}_{18}=1.037, \mathrm{P}=0.3134\right)$. (G) Experimental paradigm for contextual fear conditioning and test. Mice were trained in context $\mathrm{A}$ and received a footshock, and freezing was tested 24 hours later in the same context. (H) 2 mo and 10 mo mice showed similar freezing in single-trial contextual fear memory test. (2 mo $\mathrm{n}=10$ mice, 10 mo $\mathrm{n}=10$ mice, two-tailed unpaired $\mathrm{t}$-test, $\left.\mathrm{t}_{18}=0.3124, \mathrm{P}=0.7584\right)$. (I) Representative confocal images showing $\mathrm{DCX}^{+}$cells in the DG of 2 mo and 10 mo mice. Scale bar: $20 \mu \mathrm{m}$. (J) Density of $\mathrm{DCX}^{+}$cells in the DG of 2 mo and 10 mo mice. ( 2 mo $n=4$ mice, 10 mo $n=4$ mice, two-tailed unpaired $t$-test, $t_{6}=5.044$, $* * \mathrm{P}=0.0 .0023)$ 
Figure EV3. Loss of Lin28a from NPCs resulted in decreased neurogenesis, and the effect on animals'

behaviors. (A) Experimental paradigm for contextual fear conditioning and test. Six weeks after Veh or

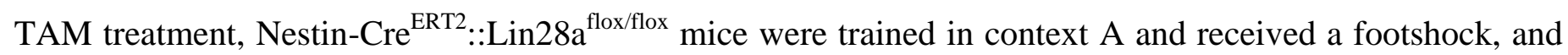
freezing was tested 24 hours later in the same context. (B) Loss of Lin28a from hippocampal NPCs did not alter freezing of mice during the single-trial contextual fear memory test. (Veh $n=13$ mice, TAM n=10 mice; two-tailed unpaired t-test, $\left.\mathrm{t}_{21}=0.02071, \mathrm{P}=0.8379\right)$. (C) Experimental paradigm for novel object recognition test. (D) Loss of Lin28a from hippocampal NPCs did not impair the novel object recognition of TAM-treated Nestin-Cre ${ }^{\text {ERT2 }}::$ Lin28a ${ }^{\text {flox/flox }}$ mice. $\left(\right.$ Veh $n=14$ mice, two-tailed paired t-test, $\mathrm{t}_{13}=3.769, * * \mathrm{P}=0.0023 ;$ TAM $\mathrm{n}=10$ mice, two-tailed paired $\mathrm{t}$-test, $\left.\mathrm{t}_{9}=2.908, * \mathrm{P}=0.0174\right)$. (E) Veh- and TAM- treated mice showed similar discrimination index between novel and familiar objects. (Veh $n=14$ mice, TAM n=10 mice, two-tailed unpaired t-test, $\mathrm{t}_{22}=0.3452, \mathrm{P}=0.7332$ ). (F) Experimental paradigm for novel location recognition test. (G) Loss of Lin28a from hippocampal NPCs impaired the novel location recognition of TAM-treated Nestin$\mathrm{Cre}^{\mathrm{ERT} 2}::$ Lin28 $\mathrm{a}^{\text {flox/flox }}$ mice. $\left(\right.$ Veh $\mathrm{n}=14$ mice, two-tailed paired t-test, $\mathrm{t}_{13}=5.355, * * * \mathrm{P}=0.0001 ; \mathrm{TAM} \mathrm{n}=12$ mice, two-tailed paired t-test, $\left.\mathrm{t}_{11}=1.896, \mathrm{P}=0.0845\right)$. (H) Loss of Lin28a from hippocampal NPCs decreased the discrimination index between novel and familiar locations. (Veh n=14 mice, TAM n=12 mice, two-tailed unpaired t-test, $\mathrm{t}_{24}=2.189, * \mathrm{P}=0.0386$ ). 
A

DAPI

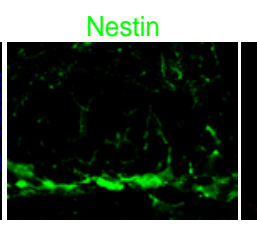

mRNA
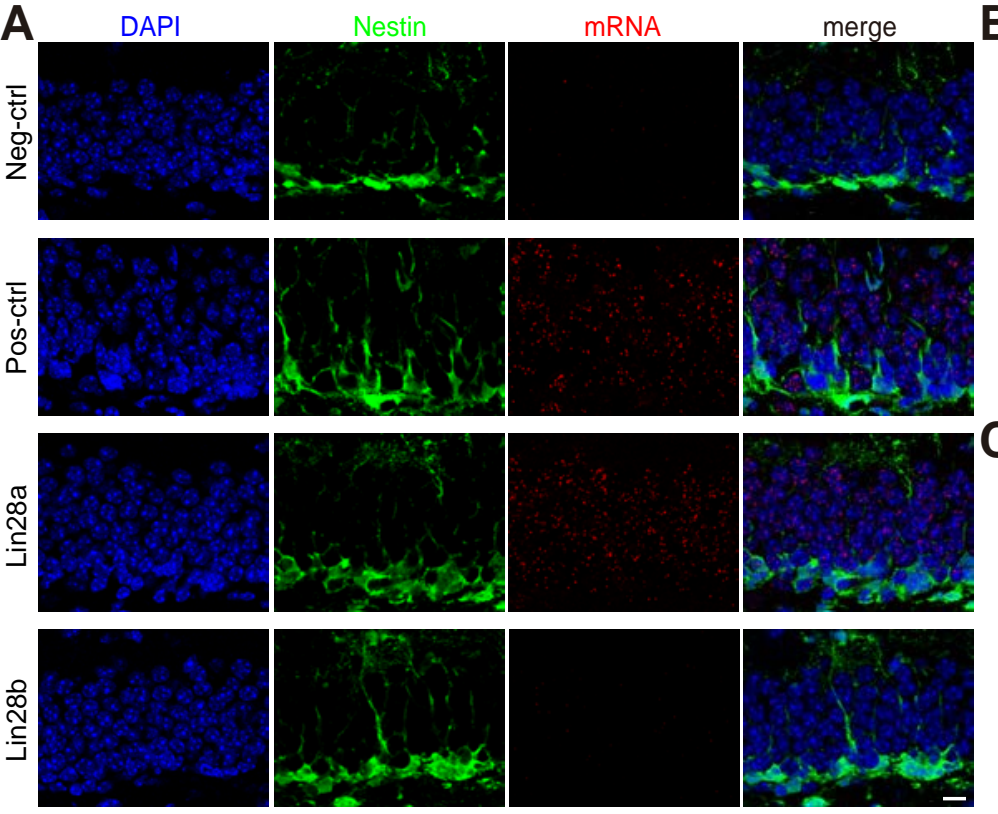

F
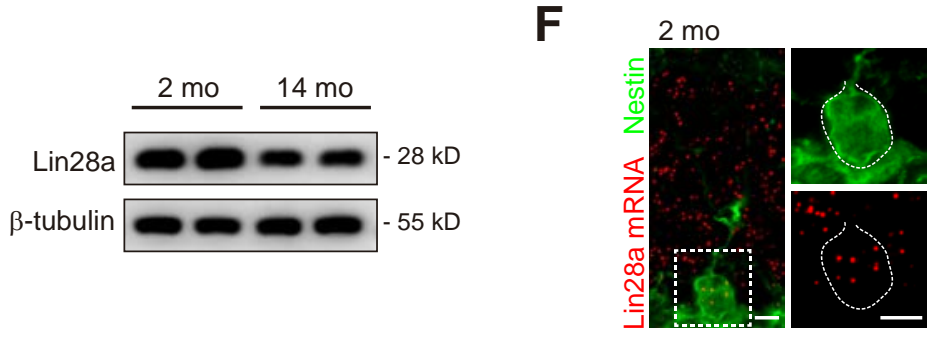

H

E

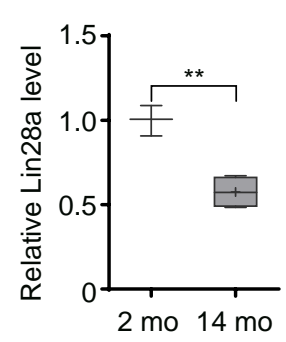

D

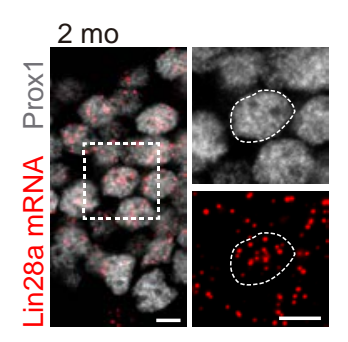

H

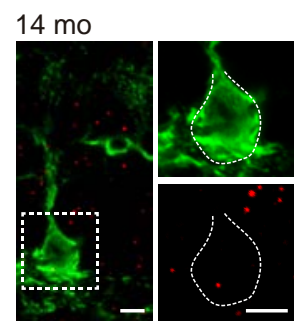

G
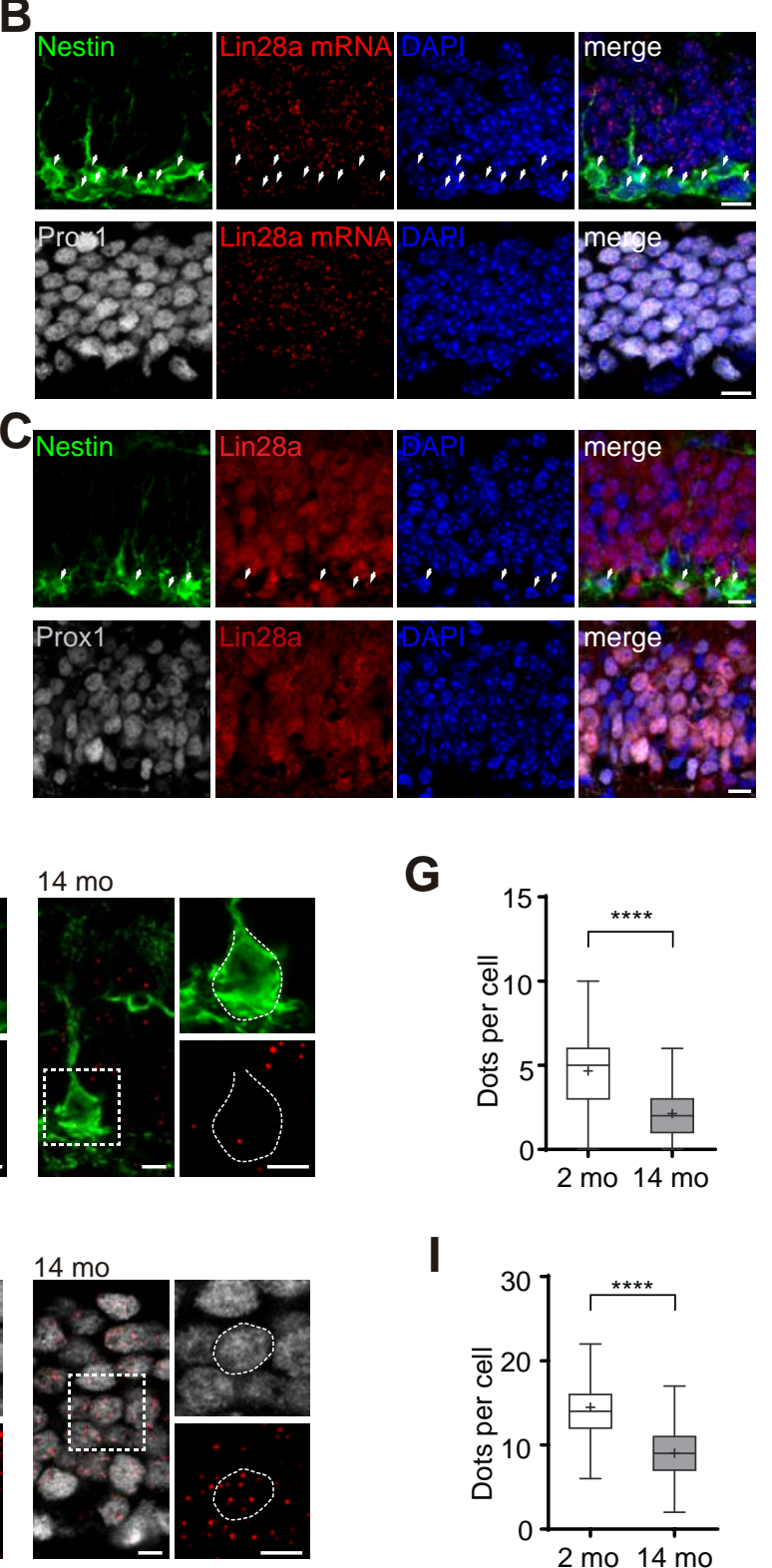

G

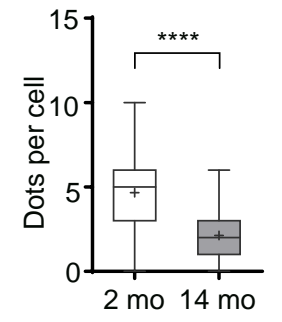

I

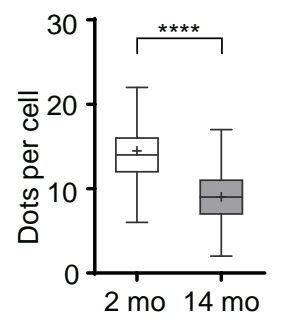


Fiqure 2 bioRxiv preprint doi: https://doi.org/10.1101/2022.01.03.474756; this version posted January 4, 2022. The copyright holder for this preprint (which was not certified by peer review) is the author/funder. All rights reserved. No reuse allowed without permission.

A

\begin{tabular}{|c|c|c|c|c|c|c|c|c|c|c|c|c|c|}
\hline Training days & $\frac{0}{2}$ & $\frac{1}{5}$ & B & $\frac{3}{A}$ & 4 & 5 & $\frac{6}{A}$ & $\begin{array}{l}7 \\
B\end{array}$ & 8 & $\frac{9}{A}$ & 10 & 11 & $\frac{12}{A}$ \\
\hline & & B & $F_{A}$ & B & A & $z_{A}$ & B & A & B & B & A & A & B \\
\hline Test sessions & & & & & & & & & & & & & \\
\hline
\end{tabular}

B
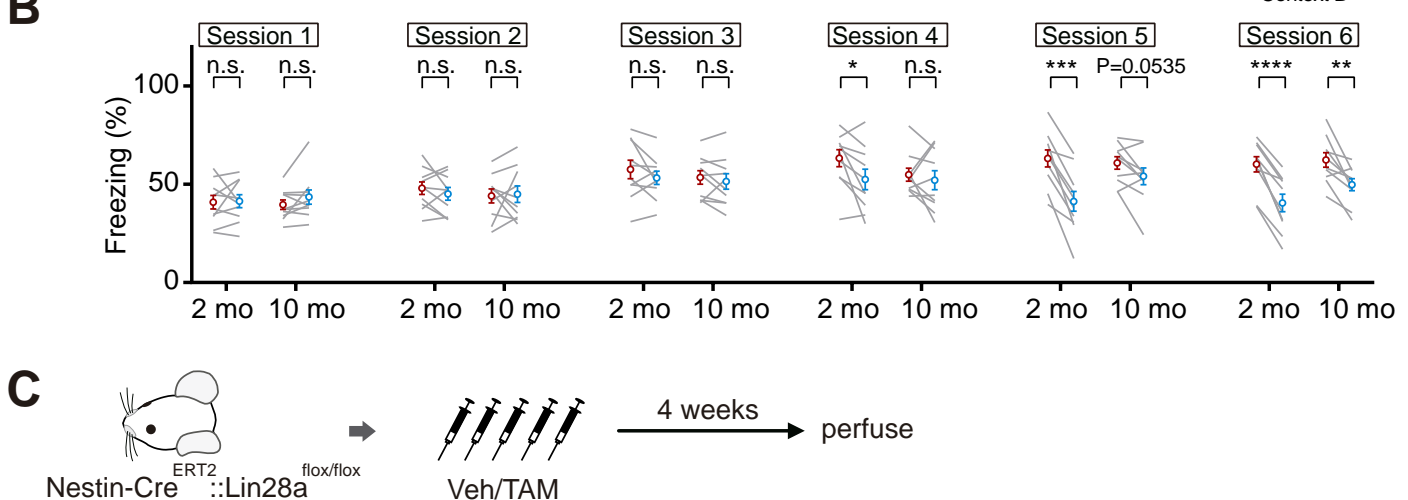

D

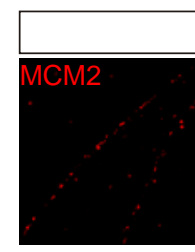

G
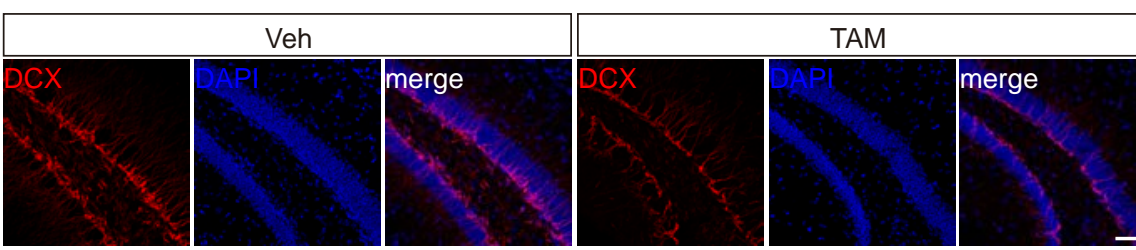

J

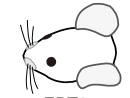

Nestin-Cre $\stackrel{\text { ERT2 }}{:: \text { Lin28a }}{ }^{+/+}:$Ai14 or Nestin-Cre $\stackrel{\text { ERT2 }}{:}$ :Lin28a ${ }^{\text {floxflox }}:$ :Ai14

K
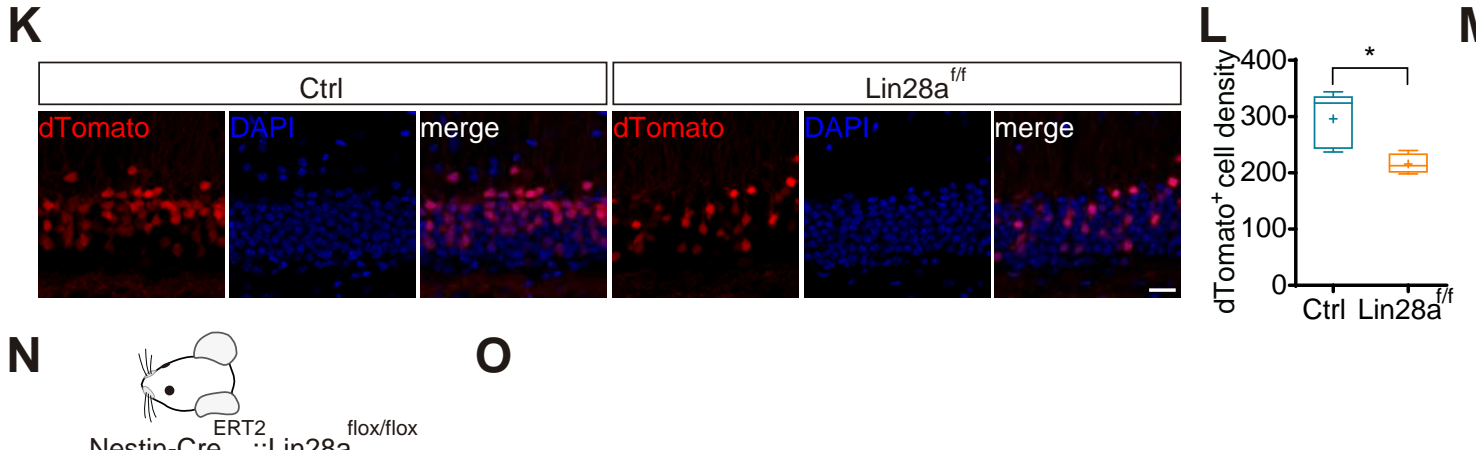

\section{0} Nestin-Cre ${ }^{\text {ERT2 }}:$ Lin28a flox/flox $^{-2}$

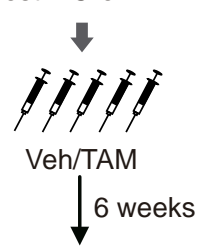

behavior tests
E
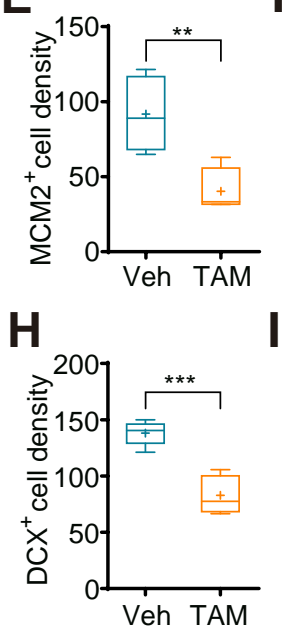

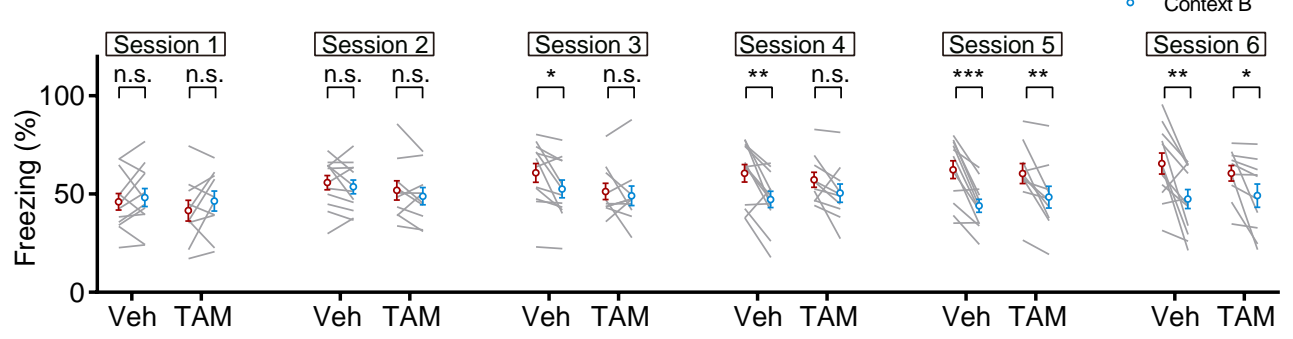

F
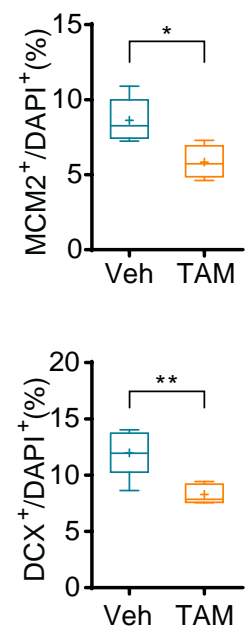

M

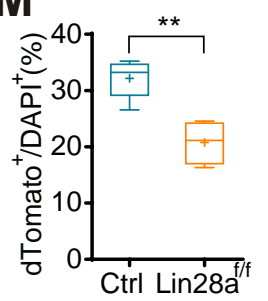

- Context A

- Context B 
Figure 3 bioRxiv preprint doi: https://doi.org/10.1101/2022.01.03.474756; this version posted January 4, 2022. The copyright holder for this preprint (which was not certified by peer review) is the author/funder. All rights reserved. No reuse allowed without permission.

A
Retroviral vectors

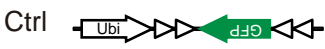 Lin28a-OE $\neg$ Ubi $>\gg \triangleright$

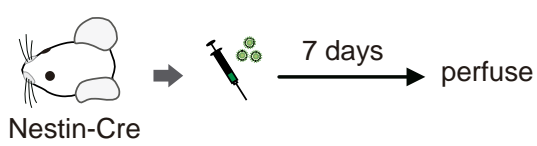

B

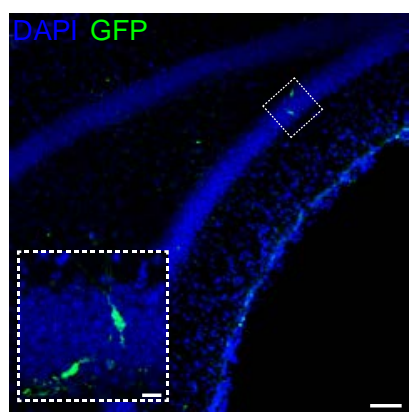

C

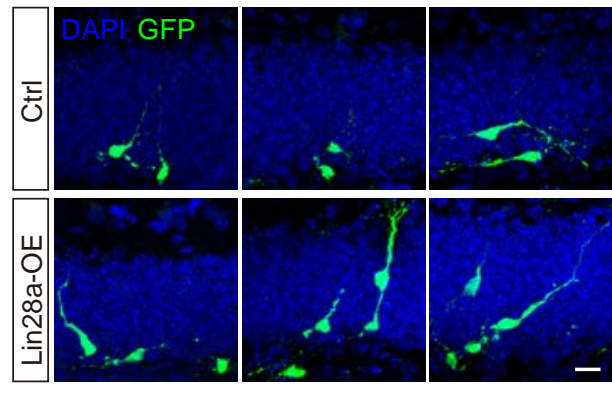

D

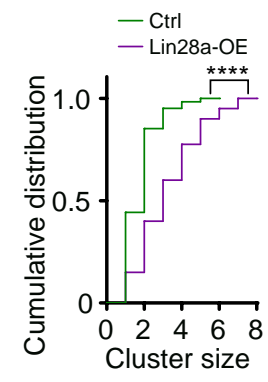

H

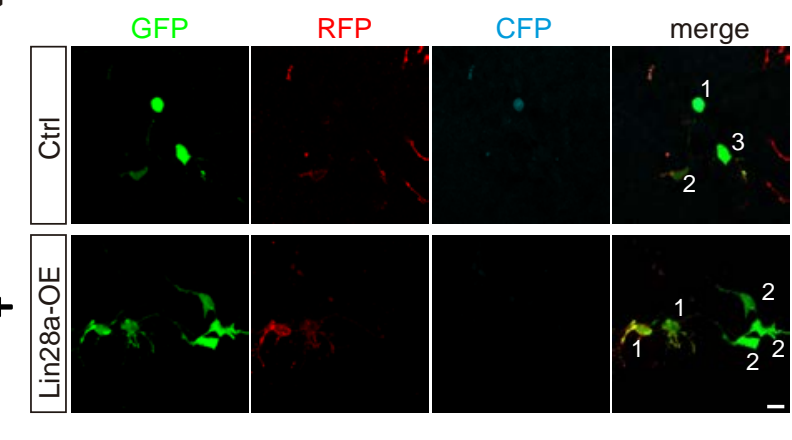

$\mathbf{E}$

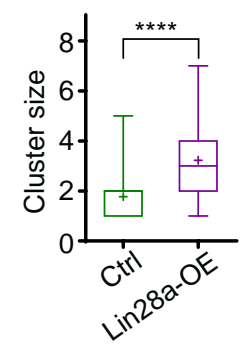

I
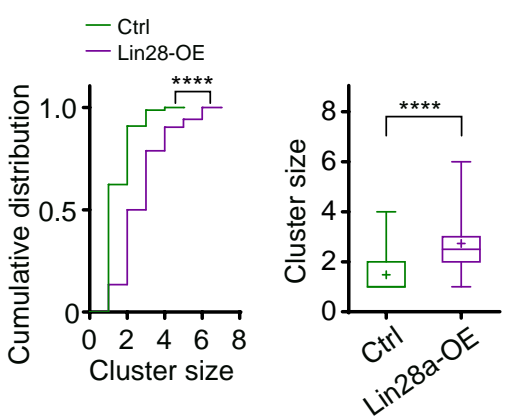

$\mathrm{m} / \mathrm{n} / \mathrm{cXFP}$ retroviral vectors Ctrl

$\Rightarrow$ Ubi $>\infty>d \pm 90<-$

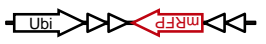

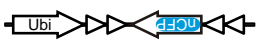
Lin28a-OE $\square$ Ubi $>\curvearrowright<$ ह8zul] सzव

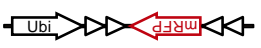

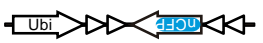

\section{G}

F

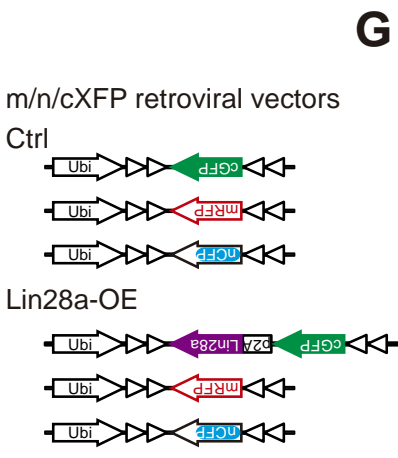


A

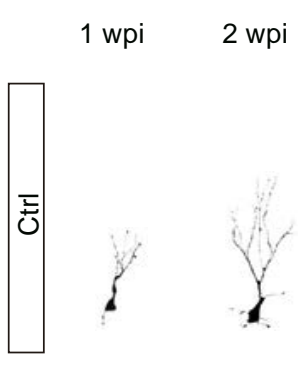

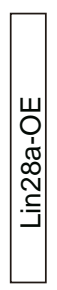

E

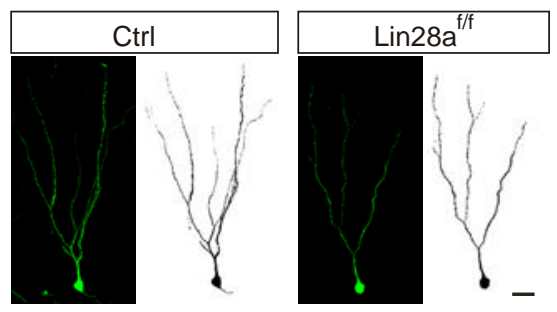

B

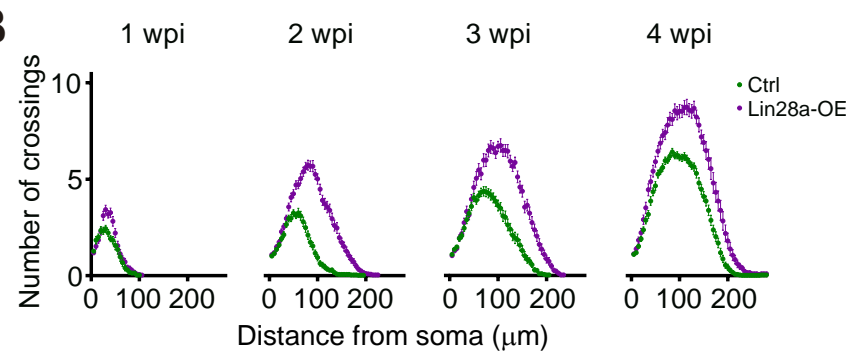

C

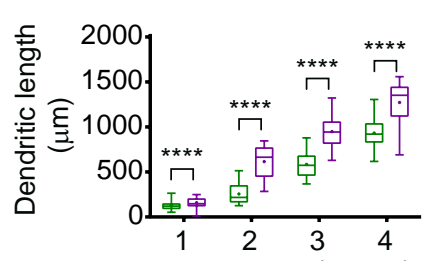

Time post injection (weeks)
D

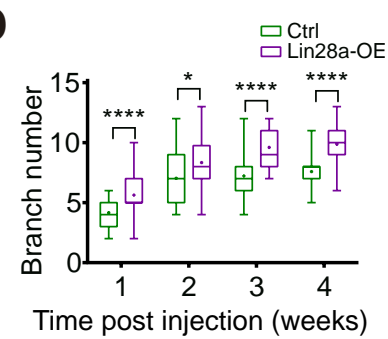

G

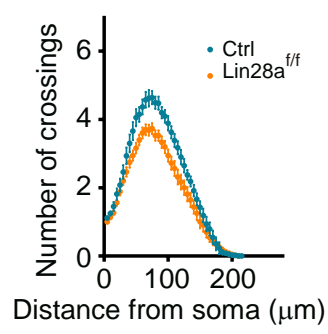

H
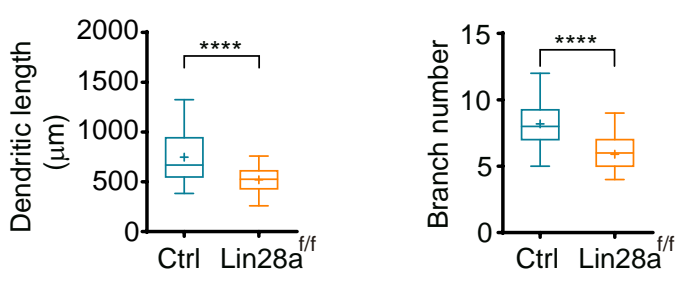

I
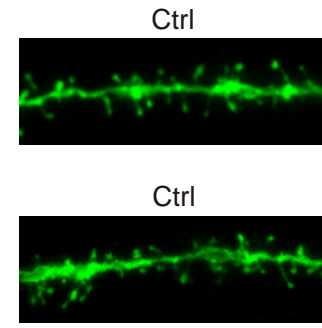

Lin28a-OE

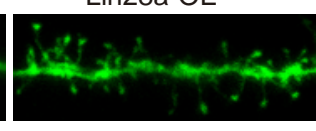

$\operatorname{Lin} 28 a^{f / f}$

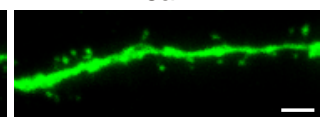

J

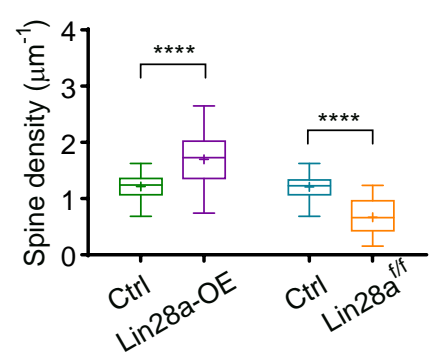

K

Lin28a-OE

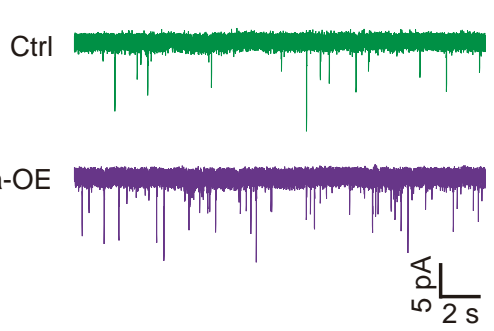

L

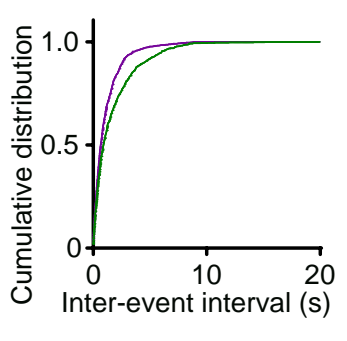

$\mathbf{N}$

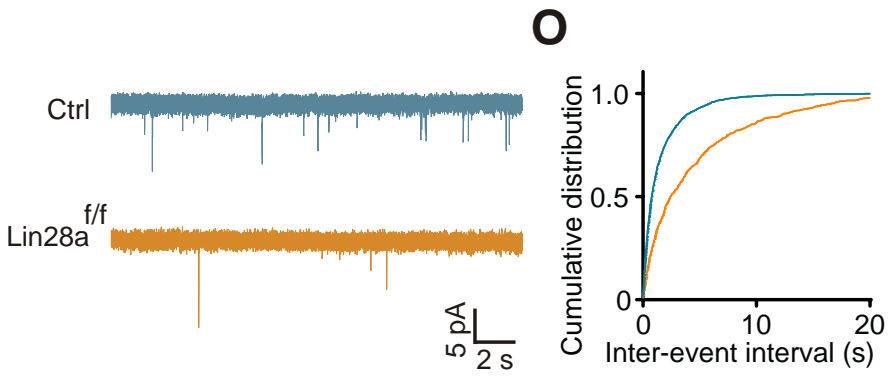

M

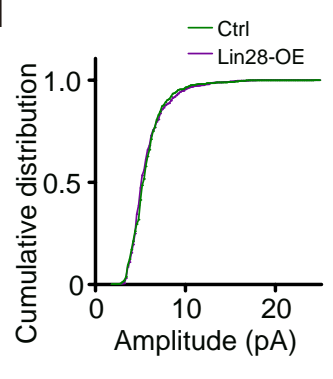

$\mathbf{P}$

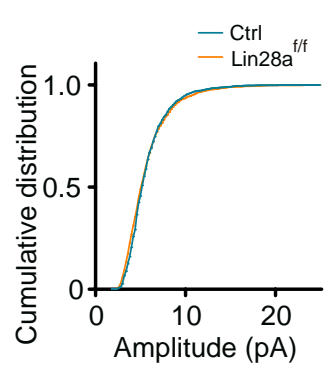

Q

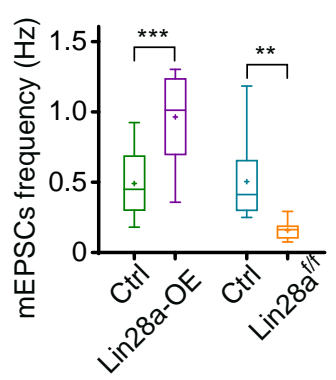

$\mathbf{R}$

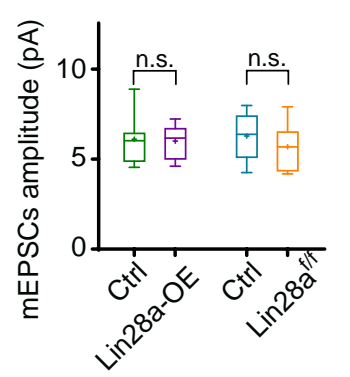




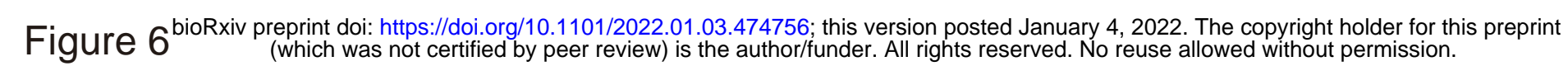

A

Lentiviral vectors

GFP $\square$ GDI

Wnt3a
B

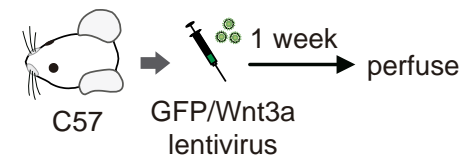

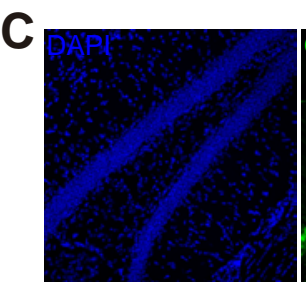

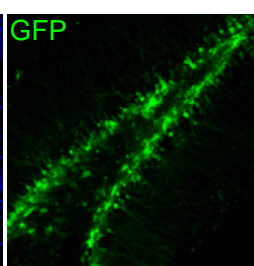

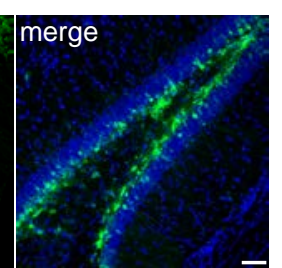

D GFP Wnt3a

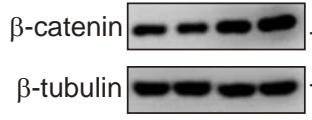
$-90 \mathrm{kD}$
$-55 \mathrm{kD}$

E

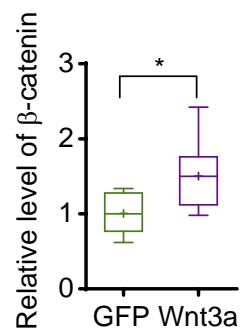

$F$
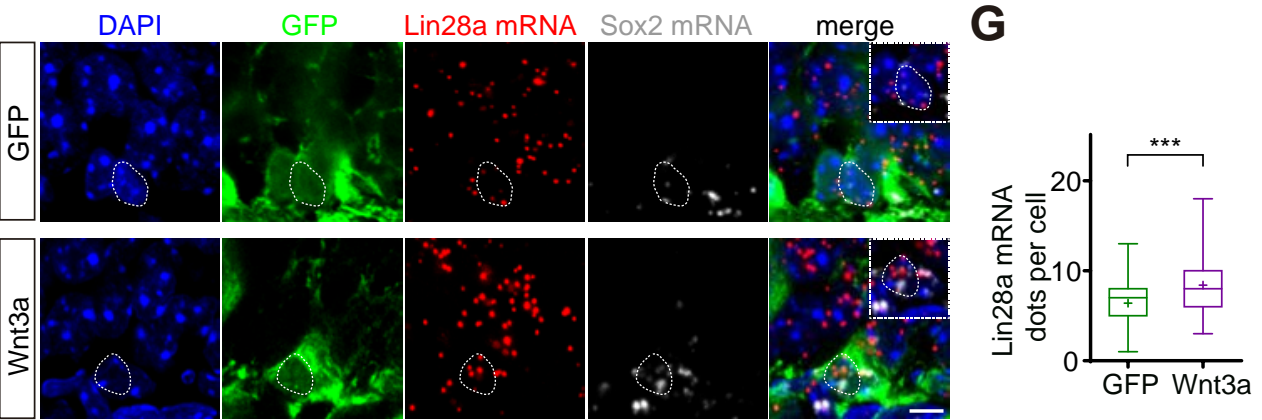

H

Lentiviral vectors
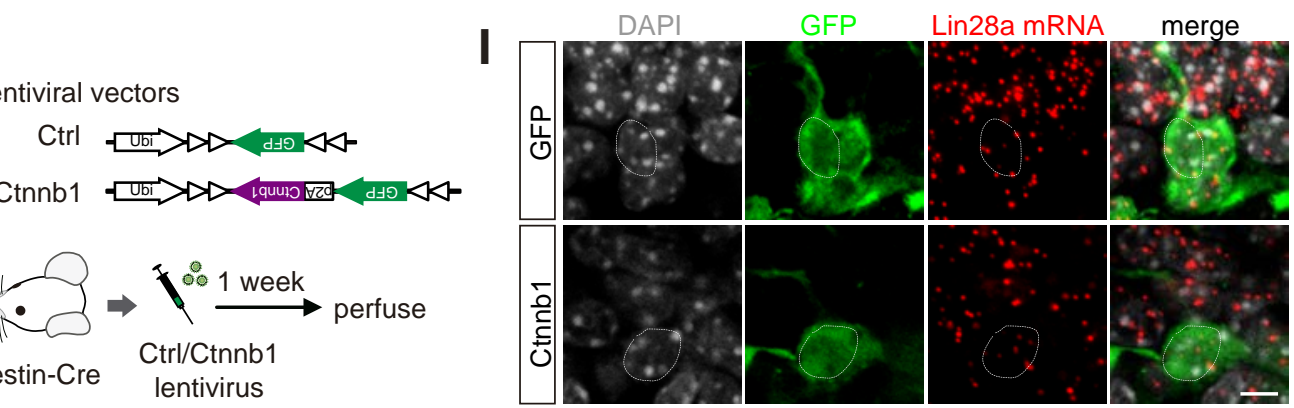

J

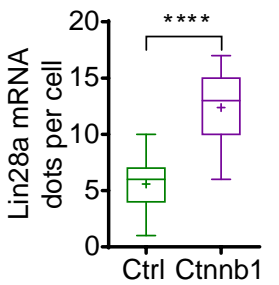




\section{Figure 7 bioRxiv preprint doi: https://doi.org/10.1101/2022.01.03.474756; this version posted January 4,2022 . The copyright holder for this preprint
(which was not certified by peer review) is the author/funder. All rights reserved. No reuse allowed without permission.}

A

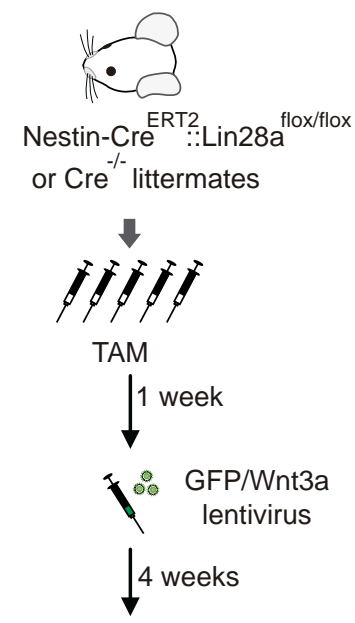

perfuse

E

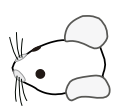

Nestin-Cre $\stackrel{\text { ERT2 }}{: \text { Lin28a }} \stackrel{\text { flox/flox }}{: \text { Ai14 }}$ or Nestin-Cre ${ }^{\text {ERT2 }}:$ Lin28a $^{+/+}:: A i 14$

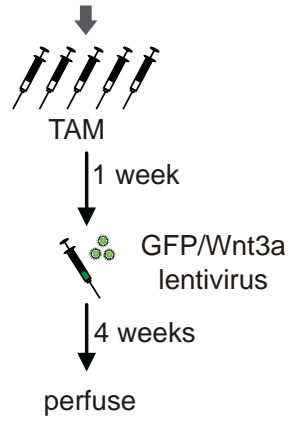

Lentiviral vectors

dTomato - $>$ dTomato-

dnWnt1 $\longrightarrow$ Ubi dnWnit p2AdTomato-

Lentiviral vectors

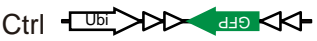

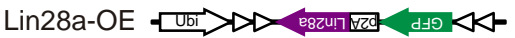
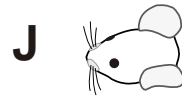

Nestin-Cre

$$
\checkmark
$$

- dTomato/dnWnt1

lentivirus

$\downarrow 2$ weeks

$\because \mathrm{Ctrl} / \mathrm{Lin} 28 \mathrm{a}-\mathrm{OE}$

lentivirus
14 weeks
perfuse

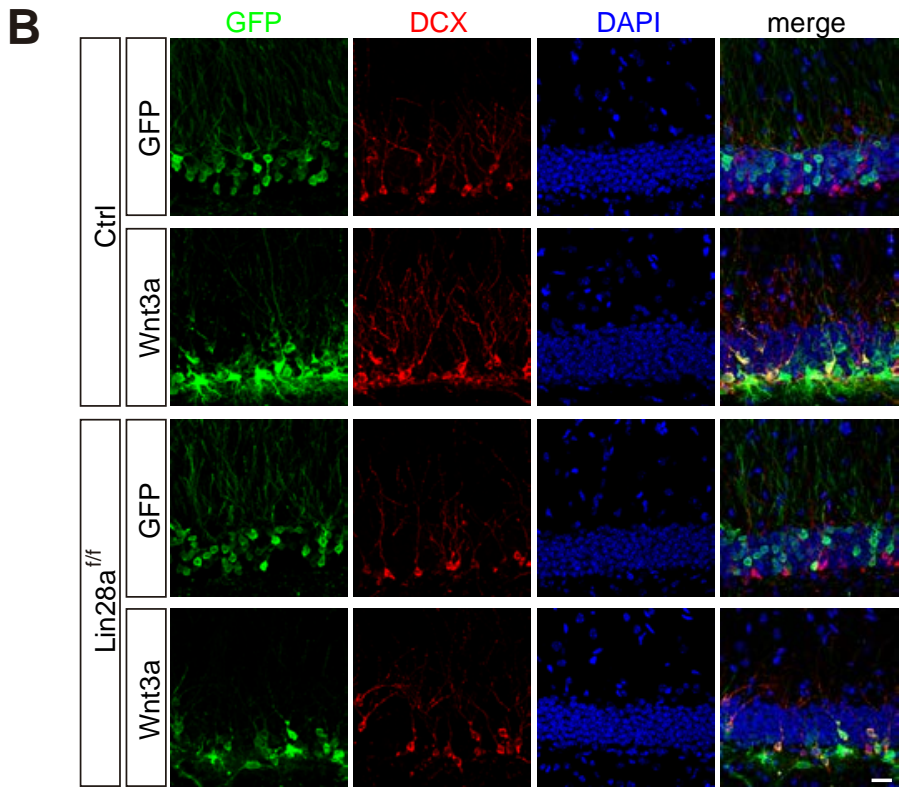

$\mathbf{F}$

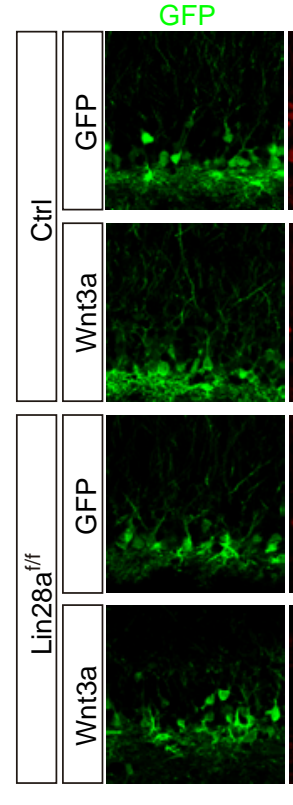

dTomato

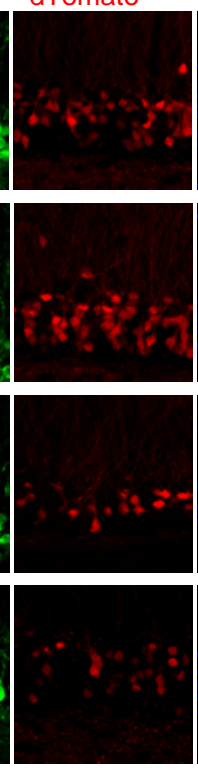

DAPI

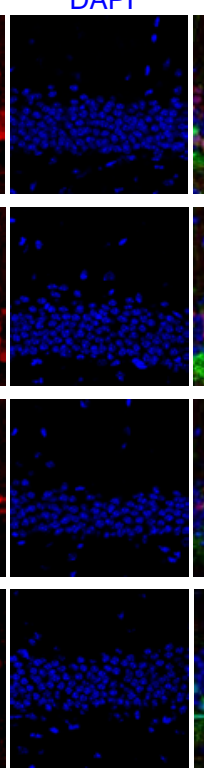

C

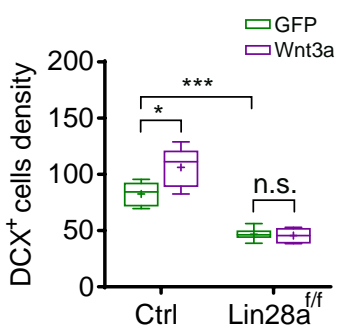

D

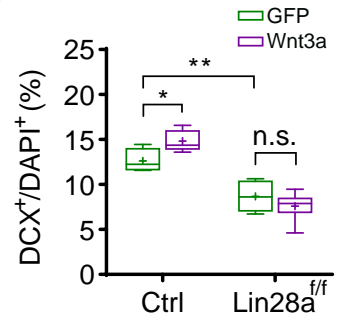

G

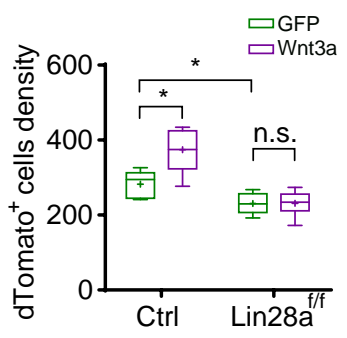

H

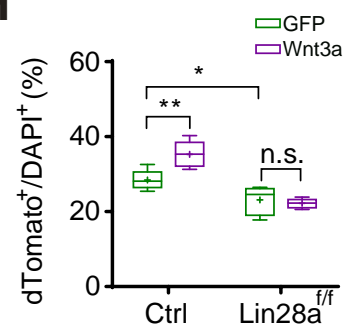

K

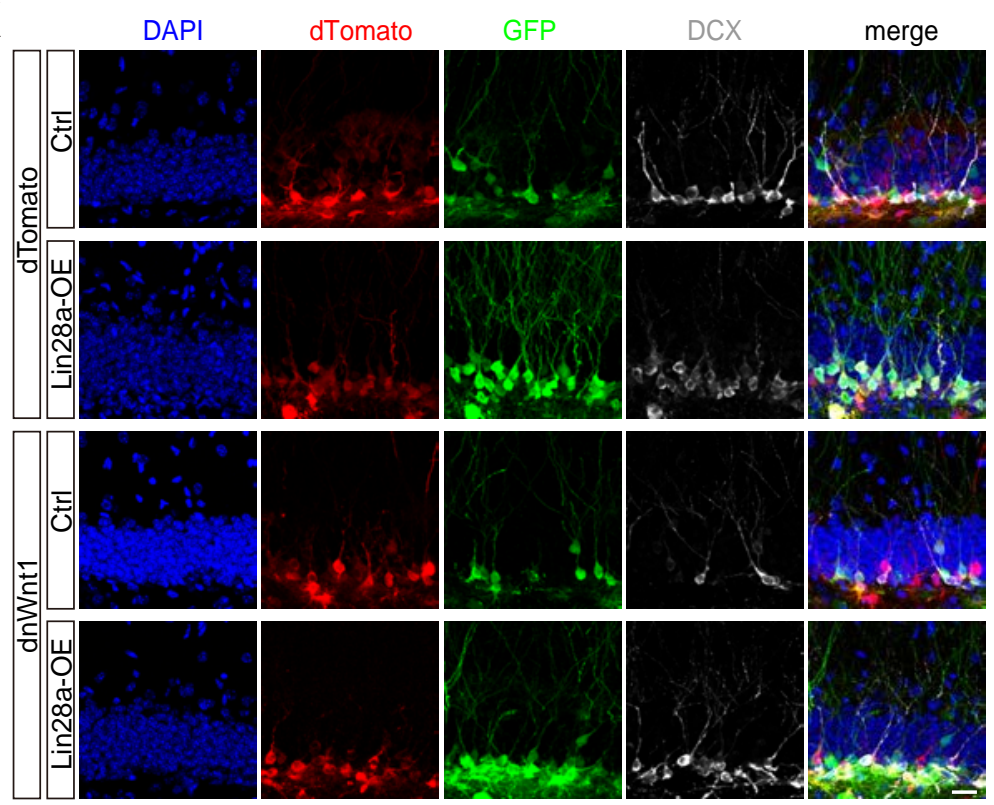


Figure 8bioRxiv preprint doi: https://doi.org/10.1101/2022.01.03.474756; this version posted January 4, 2022. The copyright holder for this preprint (which was not certified by peer review) is the author/funder. All rights reserved. No reuse allowed without permission.

A Lentiviral vectors

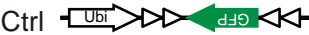

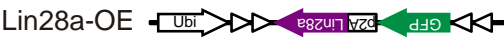

B

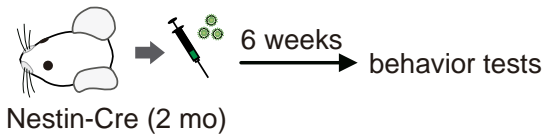

C
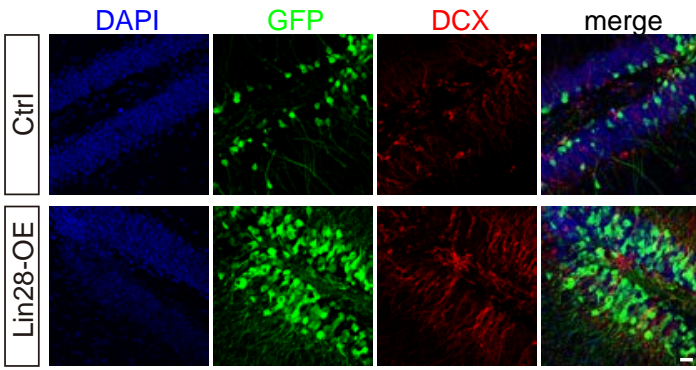

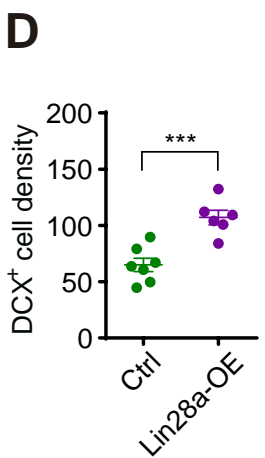

E

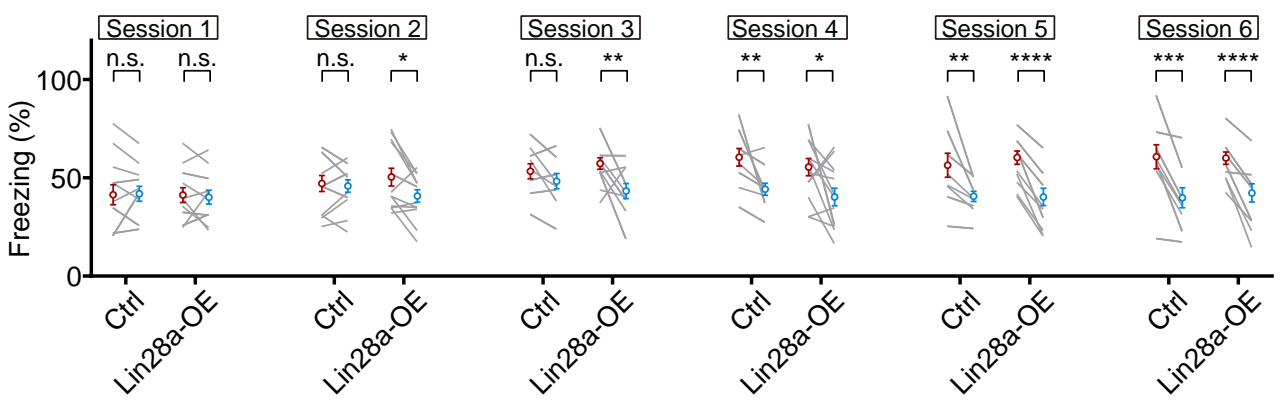

$\mathbf{F}$

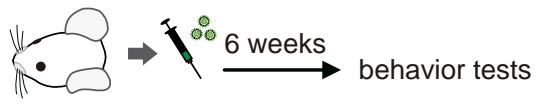

Nestin-Cre (12 mo)
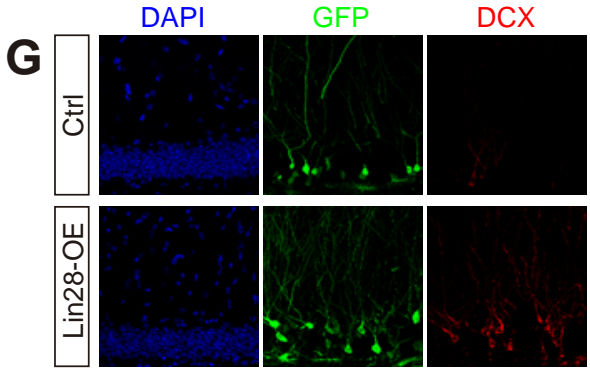

merge

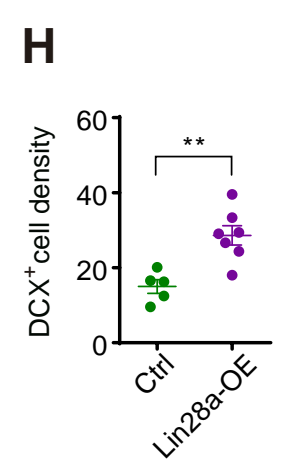

\section{I}

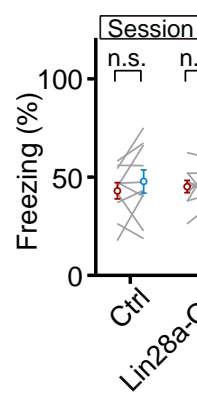

S.s. n.s.

Session 3

Session 4

Session 5

- Context A

Context B
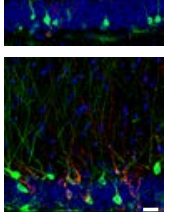

n.s. n.s. n.s.
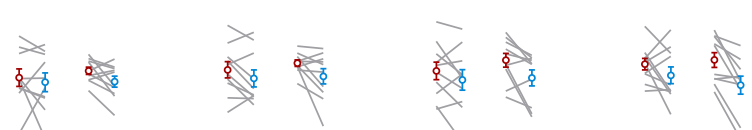